\title{
Guillaume-Thomas Raynal oder Figuren und Funktionen des Lesens in der europäischen Aufklärung
}

Beginnen wir unsere Reise durch die Geschichte im 18. Jahrhundert. Denn dieses Siècle des Lumières, dieses Jahrhundert der Aufklärung ist zugleich auch ein Jahrhundert der Lektüre und des Lesens. Wie wir schon in unserer theoretischen Annäherung an die Geschichte des Lesens sahen, ereigneten sich umwerfende Umwälzungen des Lesens in einem Jahrhundert, das im Zeichen jener großen politischen Revolution steht, die von Frankreich aus die Welt erhellte. Daran war, um es etwas verkürzt zu sagen, das Lesen nicht unschuldig, oder anders: Ohne die Macht und Kraft der Lektüre wäre die Französische Revolution nicht vorstellbar gewesen.

Wir können aus heutiger Perspektive von einer europäischen Doppelrevolution sprechen, die mit der industriellen Revolution in England und der politischen in Frankreich die entscheidenden Veränderungen brachte, die weit über das 18. und 19. Jahrhundert hinaus ihre Wirkung entfalten sollten. Vergessen wir neben dieser europäischen aber nicht die amerikanische Doppelrevolution, die mit der antikolonialen Unabhängigkeitsrevolution der USA begann und mit der gegen die Sklaverei gerichteten Revolution auf Haiti nach über einem Jahrzehnt erbitterter Kämpfe im Jahre 1804 zu ihrem Abschluss gelangte.

In seiner berühmten, 1815 in seinem Zufluchtsort Kingston verfassten Carta de Jamaica verlieh Simón Bolivar seiner Hoffnung auf eine nationale und kontinentale Befreiung vom spanischen Joch Ausdruck, wobei er sich explizit auch auf jenen Autor bezog, dessen Name seit 1780 die Titelseite der erstmals 1770 veröffentlichten Histoire des deux Indes zierte:

Trotz alledem werden die Mexikaner frei sein, denn sie haben die Sache des Vaterlandes ergriffen, entschlossen, ihre Vorfahren zu rächen oder diesen ins Grab zu folgen. So sagen sie bereits mit Raynal: Endlich ist die Zeit gekommen, um den Spaniern Gräueltaten für Gräueltaten heimzuzahlen und diese Rasse von Massenmördern in ihr Blut oder ins Meer zu werfen. ${ }^{1}$

1 Bolívar, Simón: Carta de Jamaica. The Jamaica Letter. Lettre à un Habitant de Jamaïque. Caracas: Ediciones del Ministerio de Educación 1965, S. 58. 


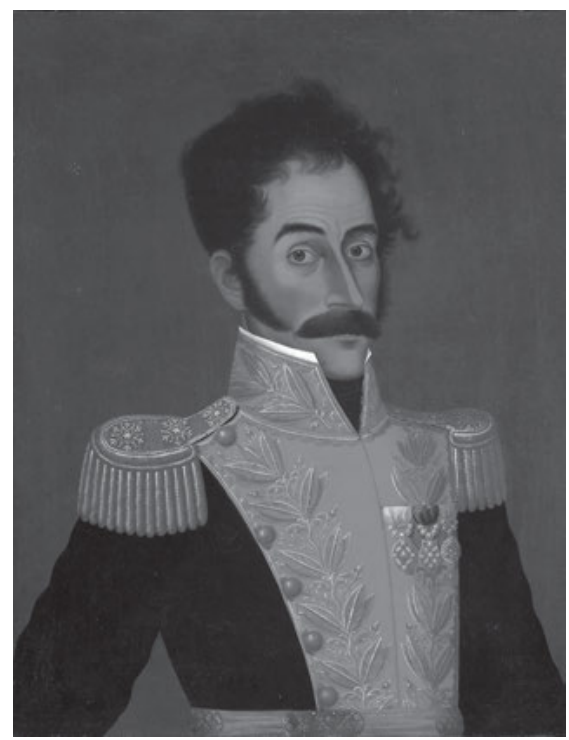

Abb. 62: Simón Bolívar (Caracas, Neugranada, 1783 - Santa Marta, Großkolumbien, 1830), circa 1823-1825.

Simón Bolívar zitierte in seiner berühmten Carta ganz bewusst Raynal, den Verfasser eines der großen Bestseller des 18. Jahrhunderts und Organisator der wichtigsten Kolonialenzyklopädie der Aufklärung, weil dessen Lektüre in jenen Kreisen, die sich für eine Unabhängigkeit, für die Independencia der spanischen Kolonien einsetzten, selbstverständlich vorausgesetzt werden konnte. In diesem für ein Verständnis des Libertador grundlegenden Text griff der Vertreter der jungen kreolischen Eliten des künftigen Venezuela auf den Namen des französischen Philosophen nicht etwa zurück, um seine politischen und ideologischen Überzeugungen zu begründen, sondern um sich seiner eher als Waffe im Kampf der Texte und Diskurse gegen ein Spanien zu bedienen, dessen zwischenzeitlich verstärkte Truppen in den Kolonien eine Reihe von Siegen über die Aufständischen errungen hatten. Der Rückgriff auf die Lektüre und den Namen Raynals war von bedeutender Schlagkraft im Kampf um die Zukunft der künftigen amerikanischen Republiken.

Gerade in den Kolonien galt Raynal als der führende Vertreter der französischen Aufklärung und als einer jener entscheidenden Köpfe, welche die Französische Revolution in die Wege geleitet hatten. Doch ohne jeden Zweifel handelte es sich bei Bolívars Verweis auf Guillaume-Thomas Raynal um ein eher zweischneidiges Schwert im Kampf um die Unabhängigkeit. Denn der französische philosophe - der bei den aufgeklärten amerikanischen Kreolen noch immer unbestritten als der Verfasser der Histoire des deux Indes galt - war zwar für seine vehementen Ausfälle gegen die Spanier und ihr ebenso ungerechtes wie ineffizientes Kolonialsystem berühmt geworden, doch wussten die Angehörigen der kreolischen 
Oberschicht nicht weniger um seine Angriffe auf die Dekadenz, die Trägheit und Unfähigkeit der Bewohner des südlichen Amerika.

Dabei schloss der französische Aufklärer sehr wohl die Kreolen in sein negatives Bild mit ein, denen er und andere europäische Autoren des 18. Jahrhunderts vorwarfen, sich nicht selbst regieren und eigene Regierungsformen geben $\mathrm{zu}$ können. Raynal war deshalb alles andere als ein Parteigänger dieser Kreolen, die als Trägerschicht der Unabhängigkeitsrevolution die Geschicke der entstehenden Republiken an sich zogen. Derlei Negativbilder und Anschuldigungen hatten den Ruf und das Prestige des französischen Philosophen in den intellektuellen Zirkeln der amerikanischen Kolonien daher auch stark beschädigt.

Nicht umsonst hatten in Neu-Spanien die herausragenden ,mexikanischen“ Vordenker wie Francisco Xavier Clavijero oder Fray Servando Teresa de Mier y Guerra eine Polemik gegen europäische Philosophen wie de Pauw, Robertson oder Raynal in Gang gesetzt. Sie hatten sich in den sogenannten Disput um die Neue Welt gegen jene Vertreter der europäischen Geisteswelt eingeschaltet, die versucht hatten, die abwertenden Urteile Montesquieus oder Buffons gegenüber Amerika und seinen Bewohnern weiter zu fassen und zu radikalisieren. ${ }^{2}$ Auch in der sogenannten Berliner Debatte um die Neue Welt ging es wesentlich um das Bild der Bewohner Amerikas und die vorurteilsbeladenen Ansichten, die von Europa aus im Jahrhundert der Aufklärung über diese verbreitet wurden. ${ }^{3}$

Wenn die Rezeption des Raynal'schen Werkes in Lateinamerika auch von einer grundlegenden Ambivalenz gekennzeichnet war, so konnte die Histoire des deux Indes - und insbesondere ihre zahlreichen, gegen die spanische Kolonialverwaltung gerichteten Anklagen und Vorwürfe - doch als eine wichtige Waffe für jene, die für eine politische Selbständigkeit der spanischen Kolonien kämpften, von großem Nutzen sein. Denn die Lektüre und die Berufung auf die aufklärerischen Texte, die im Namen Raynals veröffentlicht wurden, konnten sehr wohl die Legitimität und die Herrschaftsbefugnis des spanischen Mutterlandes in seinen überseeischen Kolonien untergraben. Um diese subversive Funktion ging es im Kern. Die angeführte Passage belegt, dass keineswegs nur Simón Bolívar um die subversive Kraft dieses vielgestaltigen und widersprüchlichen Werkes wusste. Auch die spanische Kolonialverwaltung kannte diese Gefahr, so dass man von kolonialspanischer Seite her bald schon versuchte, ein Gegengewicht zur gefähr-

2 Vgl. hierzu die längst klassische Studie von Gerbi, Antonello: La disputa del nuovo mondo. Storia di una polemica: 1750-1900. Nuova edizione a cura di Sandro Gerbi. Con un profilo dell'autore di Piero Treves. Mailand - Neapel: Riccardo Ricciardi editore 1983.

3 Vgl. hierzu Bernaschina, Vicente / Kraft, Tobias / Kraume, Anne (Hg.): Globalisierung in Zeiten der Aufklärung. Texte und Kontexte zur „Berliner Debatte“ um die Neue Welt (17./18. Jh.). Teil 1. Frankfurt am Main - Bern - New York: Peter Lang Edition 2015. 
lichen Wirkung von Raynals Attacken auf die aufgeklärte kreolische Elite zu schaffen. Lesen war im Zeitalter der Aufklärung eben eine subversive Angelegenheit: Es konnte staatsumstürzende, und in diesem Falle die Independencia fördernde Folgen nach sich ziehen: eine hochpolitische Tätigkeit also, mit der wir es hier am Übergang zum 19. Jahrhundert zu tun haben. Leser waren potentiell gefährlich!

Dies mag die dauerhaften Anstrengungen von spanischer Seite erklären, eine offizielle Geschichte des eigenen Kolonialreiches und der heroischen spanischen Conquista vorzulegen. ${ }^{4}$ Sie beruhte auf einigen der spanischen Krone allein zugänglichen Informationen - und hierzu zählten nicht nur die Kolonialarchive, sondern auch eine Reihe von Berichten spanischer Reisender, die in spanischem Auftrag die Kolonien besuchten. Längst war ein Kampf um die sich im 18. Jahrhundert durch die Leserevolution herausgebildete Öffentlichkeit und die sogenannte,öffentliche Meinung‘ entbrannt.

Den Spaniern gelang es freilich außerhalb Spaniens nicht, gegen die so erfolgreiche Geschichte beider Indien vorzugehen und deren Attacken in die Vergessenheit zu drängen. Guillaume-Thomas Raynals Hauptwerk war nicht allein in Frankreich, sondern auch in ganz Europa und weit darüber hinaus ein absoluter Verkaufsschlager, der die öffentliche Meinung ganz wesentlich prägte. Aller Widersprüche und Ambivalenzen zum Trotz, welche die Wirkung der Histoire des deux Indes in den Kreisen der Hispanoamerikaner beeinträchtigten, standen Raynal und sein bekanntestes Werk symbolhaft für eine Befreiung aus kolonialer Unterdrückung, waren doch viele der am Befreiungskampf auf hispanoamerikanischer Seite Beteiligten mit den berühmt gewordenen harangues in dieser Enzyklopädie der europäischen Expansion als Leser bestens vertraut. Auch in der Neuen Welt verfehlte die revolutionäre Rhetorik der Alten Welt ihre Wirkung nicht und fand Eingang in den Diskurs der Libertadores. Und diese ,Befreier` Amerikas waren zuallererst aufmerksame und begeisterte Leser.

Zweifellos ist die in der Carta de Jamaica von Simón Bolivar zu beobachtende Instrumentalisierung und Lesart Raynals nur eine unter unzähligen, die sich zwischen dem letzten Drittel des 18. und dem ersten Drittel des 19. Jahrhunderts in den künftigen Republiken eines erst in Entstehung begriffenen Lateinamerika beobachten lassen. Es handelte sich um eine populäre und in militanten Befreierkreisen sehr verbreitete Lektüreweise. Simón Bolívars bewusst gewählte Lesart ist

4 Vgl. Tietz, Manfred: Amerika vor der spanischen Öffentlichkeit des 18. Jahrhunderts. Zwei Repliken auf de Pauw und Raynal: die „Reflexiones imparciales“ von Juan Nuix y Perpiñá und die „México conquistada“ von Juan de Escoiquiz. In: López de Abiada, José Manuel / Heydenreich, Titus (Hg.): Iberoamérica. Historia - sociedad - literatura. Homenaje a Gustav Siebenmann. Bd. 2. München: Wilhelm Fink Verlag 1983, S. 989-1016. 
ein schönes Beispiel für einen ,interessierten' Lektüretyp, der uns freilich oftmals mehr über den Leser als über das Gelesene zu sagen vermag.

Doch gibt es auch andere, vielleicht weniger spektakuläre, aber darum nicht weniger interessante Lektüretypen $\mathrm{zu}$ analysieren. Beziehen wir folglich die Wirkung der Geschichte beider Indien auf die sich herausbildende Literatur der künftigen Nationalstaaten mit ein in unseren Blickwinkel. So wäre es - um bei dem von Bolívar erwähnten Raum Neu-Spaniens zu bleiben - leicht zu belegen, wieviel der erste von einem Hispanoamerikaner in Hispanoamerika geschriebene Roman El Periquillo Sarniento von José Joaquín Fernández de Lizardi einer aufmerksamen Lektüre der Histoire des deux Indes verdankt. ${ }^{5}$ Viele diskursive Elemente aus Raynals Texten wurden gleichsam in die Fiktion aufgenommen und narrativ in Bewegung gesetzt.

Von Simón Bolivar im Norden bis hin zu Domingo Faustino Sarmiento im Süden des südamerikanischen Subkontinents, von den verschiedenen Repräsentanten einer politischen und philosophischen Aufklärung in Mexico bis hin zu Vertretern der Raynal'schen Ideen in Canada: diese Enzyklopädie des europäischen Kolonialismus provozierte auf dem gesamten amerikanischen Kontinent eine Vielfalt verschiedener, aber stets produktiver Lektüren. Raynals Kolonialenzyklopädie war folglich nicht nur in Europa, sondern gerade auch in den Amerikas ein zwar verbotener Geheimtipp, zugleich aber ein Bestseller. Wie ein in Wolfenbüttel veranstaltetes Raynal-Symposium zeigen konnte, war die Wirkung des Raynal'schen Oeuvre ebenso groß und weitverzweigt wie die Divergenz der von ihm ausgelösten Lektüren. ${ }^{6}$ Dabei ist diese Divergenz der Lektüren Raynals in der Tat beeindruckend. Bevor die Histoire des deux Indes von dem nicht weniger enzyklopädischen Reisewerk Alexander von Humboldts im amerikanistischen Bereich überstrahlt wurde, hat das sicherlich nicht brisanteste, aber wohl doch weitreichendste und einflussreichste Werk des französischen Abbé eine Vielzahl von Lesarten in beiden Welten stimuliert.

Doch Lektüren und Leseweisen sind in der Geschichte beider Indien ubiquitär. Denn mag die Geschichte dieser Lektüren auch bis heute nichts von ihrer Faszination eingebüßt haben, so gilt doch, dass dieser französische Bestseller der zweiten Hälfte des 18. Jahrhunderts seinerseits auf einem weitgespannten

5 Zum Roman von Fernández de Lizardi vgl. Ette, Ottmar: Fernández de Lizardi: „El Periquillo Sarniento“. Dialogisches Schreiben im Spannungsfeld Europa - Lateinamerika. In: Romanistische Zeitschrift für Literaturgeschichte / Cahiers d'Histoire des Littératures Romanes (Heidelberg) XXII, 1-2 (1998), S. 205-237.

6 Vgl. Lüsebrink, Hans-Jürgen / Tietz, Manfred (Hg.): Lectures de Raynal. L',Histoire des deux Indes“ en Europe et en Amérique au XVIIIe siècle. Actes du colloque de Wolfenbüttel. Oxford: The Voltaire Foundation 1991. 
Gewebe von Lesevorgängen aufbaute, deren Komplexität bis heute überrascht und beeindruckt. In ihrem Bezug zur Tradition der Reisesammlungen präsentiert sich die Histoire des deux Indes unseren heutigen Augen als eine Fortsetzung und zugleich Radikalisierung der Histoire générale des voyages des Abbé Prévost. Nur dass sie eine wesentlich präziser definierte politische Funktion (und damit eben erhoffte Leseprozesse) bewusst anvisierte.

Neuere Forschungsarbeiten haben detailliert aufgezeigt, in welchem Maße Guillaume-Thomas Raynal, der „Abbé der Neuen Welt“, nicht gezögert hatte, sich der Histoire générale zu bedienen und zahlreiche Passagen dieses wichtigen Bezugstextes dekontextualisierend zu übernehmen. Mit anderen Worten: Er befleißigte sich einer plündernden Lektüre. Zwischen den Polen schöpferischer Umsetzung und simplen Plagiats oszillierend, erweist sich die écriture Raynals doch stets als hochdosierte Anverwandlung und Aneignung fremder Texte durch sehr spezifische Leseprozesse. Schreiben und Neuschreiben, Lesen und Neulesen werden zu Vorgängen, die sich nicht mehr voneinander abtrennen lassen und eine Intertextualität produzieren, die durch die beschleunigte Proliferation fremder Textfragmente und verschiedenster Informationsquellen seit der ersten Ausgabe der Histoire des deux Indes im Jahre 1770 zunehmend zentrifugalen Charakter erhielt, und so das in den frühen Rezeptionszeugnissen bereits feststellbare Bedürfnis nach einer das gesamte Werk zentrierenden Autorfigur noch erhöhte. Hierin kann man den Schlüssel für die Dynamik des Raynal'schen Oeuvre erkennen. ${ }^{7}$

Dieses Bedürfnis nach diskursiver Zentralisierung leitete schließlich zu einer wachsenden Autorisierung des über die verschiedenen Ausgaben in ständiger Expansion befindlichen kollektiven Textes über. Das zeitgenössische Lesepublikum verlangte nach einem Urheber, nach einem Gewährsmann für diese Texte. In gewisser Weise benötigte die Histoire des deux Indes nicht so sehr die Figur eines Kompilators, als vielmehr jene eines Garanten, eines Autors im modernen Wortsinn: hier liegt der Grund für die wachsende auteurisation der Histoire. Und zugleich auch die Begründung für ihren stetig wachsenden Erfolg.

Guillaume-Thomas Raynal, der mit allen Wassern der République des Lettres des 18. Jahrhunderts gewaschen war, verlieh seinem Text eine größere Autorisierung und Autorität, indem er von Ausgabe zu Ausgabe der Figur eines Autors schärfere Konturen gestattete und schließlich auch seinen zuvor mehr oder minder geheim gehaltenen (Autor-)Namen preisgab. Diese Strategie erwies sich als überaus wirksam, denn der Abbé aus dem Aveyron wurde bis zu seiner

7 Vgl. hierzu Ette, Ottmar: Diderot et Raynal: l'oeil, l'oreille et le lieu de l'écriture dans l'„Histoire des deux Indes“. In: Lüsebrink, Hans-Jürgen / Strugnell, Anthony (Hg.): L',Histoire des deux Indes“: réécriture et polygraphie. Oxford: Voltaire Foundation 1996, S. 385-407. 
berüchtigten Adresse à l'Assemblée Nationale von 1791 nicht nur als einer der großen philosophes, sondern auch als einer der „Väter der Revolution“ verehrt. ${ }^{8}$ Gleichzeitig handelte es sich um eine Textstrategie von großer Subversivität: In einer früheren, hier aber nicht nochmals zu besprechenden Untersuchung habe ich nachzuweisen versucht, auf welche Weise die Inszenierung des Philosophen in seinem Arbeitszimmer auf dem Frontispiz der dritten Ausgabe von 1780 in vier Quartbänden bei Pellet in Genf eine subtile Dekonstruktion der Autorfunktion, ganz im Sinne Foucaults enthielt. ${ }^{9}$ Dieses an poetologischen und epistemologischen Aspekten reiche Frontispiz präsentierte einen écrivain-philosophe, der nach den Aussagen der Zeitgenossen in keiner Weise jenem Manne ähnelte, den es zu re-präsentieren doch vorgab: eben Guillaume-Thomas Raynal. Seine Spiele mit der Autorschaft und mit den verschiedensten Lektüreformen und Lektürenormen sind an Komplexität, aber auch an literarischer Pfiffigkeit kaum zu übertreffen.

Auf epistemologischer Ebene ist die Welt der Histoire des deux Indes ein (Text-)Universum, das fast vollständig gegenüber der direkten Erfahrung der außereuropäischen Welt abgekapselt ist. In einer der aus Denis Diderots Feder stammenden Passagen wird dem Leser recht deutlich die epistemologische Grundlage dieser Kolonialenzyklopädie vor Augen geführt, wobei der Vergleich zwischen dem homo contemplativus und dem homme voyageur zu Ungunsten des letzteren ausfällt. Es handelt sich dabei um eine zentrale, für das Verständnis der anzusetzenden Lektüreweisen wichtige Passage, die an dieser Stelle kurz in unsere Vorlesung eingeblendet sei:

Der homo contemplativus ist sesshaft; \& der Reisende ist unwissend oder lügnerisch. Wem das Genie zuteil wurde, verachtet die genauen Details der experimentellen Erfahrung; \& wer die Experimente macht, dem mangelt es fast immer an Genie. ${ }^{10}$

Im gesamten Verlauf der Histoire des deux Indes beharrt der Erzähler in der ersten Person Singular geradezu obsessiv auf derartigen Einschätzungen und Urteilen, ${ }^{11}$ die epistemologisch von hoher Aussagekraft sind. So findet sich -

8 Vgl. hierzu Lüsebrink, Hans-Jürgen: Le rôle de Raynal et la réception de l',Histoire des deux Indes“ pendant la Révolution Française. In (ders. / Tietz, Manfred, Hg.): Lectures de Raynal, S. 85-97.

9 Vgl. Ette, Ottmar: Diderot et Raynal: l'oeil, l'oreille et le lieu de l'écriture dans l',Histoire des deux Indes“, S. 385-407.

10 Raynal, Guillaume-Thomas: Histoire philosophique et politique des établissemens \& du commerce des européens dans les deux Indes. Genf 1781, livre XI, S. 43. Ich zitiere im Folgenden nach diesem Neudruck der dritten Ausgabe unter Angabe von Buch und Seitenzahl im Text.

11 So beispielsweise auch in der folgenden Verurteilung des Reisenden: „Qu'il soit permis de le dire, il n’y a point d'état plus immoral que celui de voyageur.“ (Raynal, Guillaume-Thomas: Histoire, IX, S. 16) 


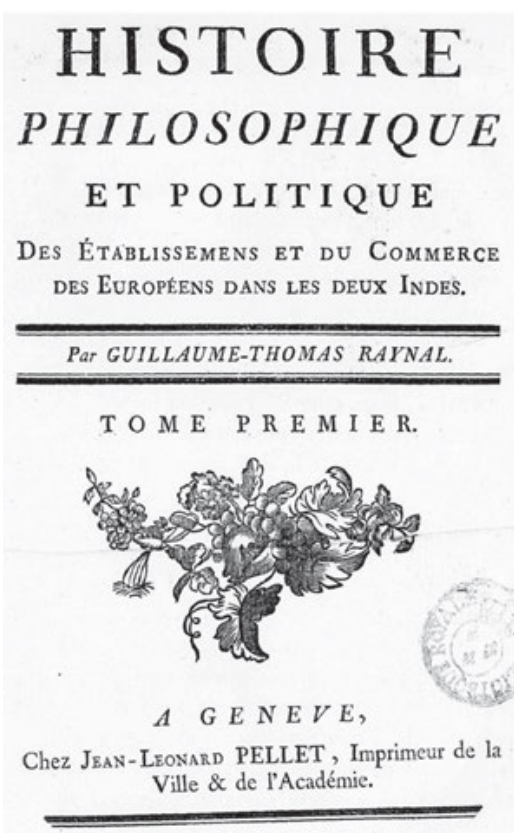

M. D C C. L X X X.

\begin{abstract}
Abb. 63a: Raynal, Guillaume-Thomas; Diderot, Denis (et alii): Histoire philosophique et politique des établissemens et du commerce des Européens dans les deux Indes, Titelblatt der 3. Ausgabe von 1780 .
\end{abstract}

um nur ein weiteres Beispiel anzuführen - im neunzehnten Buch die Opposition zwischen Reisendem und homo contemplativus in abgewandelter Form und aus etwas veränderter Perspektive wieder. Sehen wir uns diese Variante einmal näher an:

Das sesshafte Leben ist das einzige, das der Bevölkerung günstig ist; wer reist, hinterlässt keinerlei Nachkommenschaft. [...] Die großen Reiseunternehmungen haben eine neue Spezies von wilden Nomaden gezeugt. Ich will von jenen Menschen sprechen, die so viele Gegenden durchstreifen, dass sie letztlich keiner einzigen mehr angehören; die sich Frauen nehmen, wo sie sie finden, \& sie nur aus einem tierischen Bedürfnis nehmen: von jenen Amphibien, die nur an der Wasseroberfläche leben; die nur an Land für einen kurzen Augenblick gehen; für die jeder bewohnbare Strand ganz gleich ist; die in Wirklichkeit weder Väter noch Mütter noch Kinder noch Brüder noch Verwandte noch Freunde noch Mitbürger besitzen; bei denen die süßesten und heiligsten Bindungen erloschen sind; die ihrem Heimatland ohne Bedauern den Rücken kehren; die nur mit der Ungeduld dorthin zurückkehren, sogleich wieder aufzubrechen; \& denen die Gewöhnung an ein schreckliches 
Element ein gruseliges Aussehen verleiht. Ihre Rechtschaffenheit besteht die Probe der Überquerung des Äquators nicht; und sie handeln sich Reichtümer ein im Austausch für ihre Tugend \& für ihre Gesundheit. ${ }^{12}$

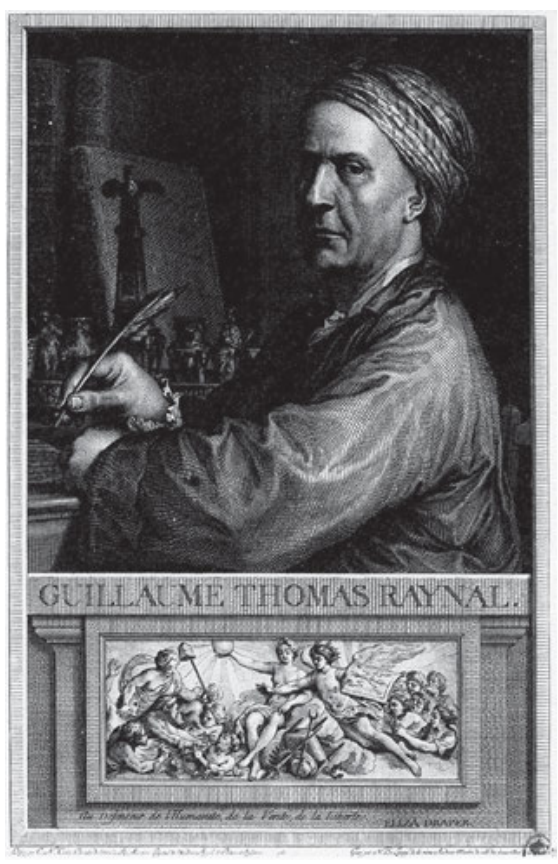

Abb. 63b: Guillaume-Thomas Raynal (Lapanouse, 1713 - Chaillot, 1796).

In dieser schönen Passage aus der Feder Denis Diderots wird von einer neuen Spezies gesprochen, die mit den großen Reisen rund um die Welt entstanden sei. Hier ist zweifellos von der zweiten Phase beschleunigter Globalisierung und von den mit ihr zusammenhängenden großen Entdeckungsreisen und Weltumsegelungen der Bougainville, Cook oder Lapérouse die Rede, die wir hier nicht näher betrachten können. ${ }^{13}$ Bei diesen Reisenden in ständiger unsteter Bewegung handele es sich um Menschen, die für ihr eigenes Vaterland keinen Sinn mehr hätten und diesem auch nicht länger von Nutzen seien.

Der nomadisierende europäische Reisende erscheint als ein moderner Wilder, dem gewisse Züge eines Ungeheuers zukommen, besitze er doch weder Vater noch Mutter noch irgendeine nennenswerte Nachkommenschaft. Durch seine ständigen

12 Raynal, Guillaume-Thomas: Histoire, XIX, S. 288f.

13 Vgl. hierzu meine frühere Vorlesung Ette, Ottmar: ReiseSchreiben. Potsdamer Vorlesungen zur Reiseliteratur. Berlin - Boston: Walter de Gruyter 2020. 
Reisen und Ortsveränderungen verliere er notwendig jedwede Integration in eine Gesellschaft und Gemeinschaft der Sesshaften, die eigentlich sein Vaterland bilden müssten. Das ist eine konfrontative Darstellung aller möglichen Forschungs- und Handelsreisenden, die zu jenem Zeitpunkt die Weltmeere bevölkerten. Welche Gründe hatte Diderot dafür? Denn dieser las sehr wohl Reiseberichte, siedelte sich aber sozusagen „oberhalb“ des Wissens an, das von den Reisenden zusammengetragen wurde und das ihm als eifrigem Leser zugänglich war. Zur Beantwortung dieser Frage scheinen mir aber noch zwei zusätzliche Aspekte von Belang.

Zunächst bildet die Überquerung des Äquators, die zum damaligen Zeitpunkt an Bord aller Schiffe mit einem Ritual gefeiert wurde, das durchaus karnevaleske Züge trug, eine Art Demarkationslinie zwischen der europäischen und der außereuropäischen Welt beider Indien. Die räumliche Verlagerung vom Mutterland in die Kolonien bringt dem Erzähler zufolge eine „Degradierung“, einen Verfall des europäischen Menschen auf allen Ebenen mit sich. In einer Passage des fünften Bandes der Histoire des deux Indes wird die Verwandlung oder Umwandlung des zivilisierten Menschen aus Europa beschrieben, ist dieser erst einmal über den Wendekreis des Krebses hinaus und in die Welt der Tropen geraten. Der zuvor zivilisierte Europäer mutiere in eine wahre Bestie. Denn er sei nicht länger Engländer, Holländer, Portugiese, Spanier oder Franzose, sondern werde zu einem geld- und goldgierigen, herrschaftssüchtigen Menschen, ja zu einem wirklichen Tier, einem „domestizierten Tiger, der zurück in den Urwald läuft“. ${ }^{14}$

Gewiss scheint die Position der Histoire des deux Indes bezüglich der Verfallserscheinungen des Menschen in den Tropen noch deutlich zurückhaltender und nuancierter als jene eines Cornelius de Pauw zu sein, der für die Europäer in den Tropen nur eine rasche und irreversible Degenerierung ausmachte. Gleichwohl findet sich etwa im siebzehnten Buch die folgende Stelle: „Die Natur scheint die Neue Welt vernachlässigt zu haben! Die Menschen sind dort weniger stark und weniger mutig, ohne Bart \& ohne Haare auf der Brust; sie sind degradiert bezüglich aller Zeichen der Männlichkeit [...]“. ${ }^{15}$ Die verbreitete europäische Schmährede von der Dekadenz der Tropenbewohner zeigt sich hier in ihrer ganzen Simplizität. Doch all diese Autoren waren nicht ein einziges Mal in Regionen gereist, die sich außerhalb von Europa befinden! Sie waren schlicht die selektiven Leser von europäischen Reiseberichten und kolportierten oder verstärkten unisono, was sie zuvor gelesen hatten.

Eine wahre Mythologie von transtropischen Klimazonen und Topographien wird hier in Bewegung gesetzt, um die „sesshafte“ Position des Nicht-Reisenden

14 Raynal, Guillaume Thomas: Histoire, IX, S. 2.

15 Ebda., XVII, S. 206. 
(oder vielleicht präziser noch: die Position dessen, der nur in einer Welt der Texte und ihrer Lektüren zu reisen pflegt) zu stärken. Es handelt sich hierbei um eine Fragestellung, welche ganz zu Beginn von Diderots Supplément au Voyage de Bougainville vorgelegt und höchst originell diskutiert wird. Dort kommt die Rede auf den Verfasser jenes Reiseberichts und insbesondere jener Darstellung Tahitis, die nicht nur in Frankreich eine wahre Südsee-Euphorie ausgelöst hatte. Denn Denis Diderot wusste sehr wohl, welch breite Rezeption Bougainvilles Reisebericht in Frankreich, ja in ganz Europa erfahren hatte:

A. Ich verstehe diesen Menschen nicht. Das Studium der Mathematik, das ein sesshaftes Leben zur Voraussetzung hat, erfüllte die Zeit seiner jungen Jahre; und nun geht er plötzlich von einer meditativen und zurückgezogenen Tätigkeit zum aktiven, mühsamen, umherirrenden und aufgespaltenen Geschäft des Reisenden über.

B. Aber keineswegs. Wenn das Schiff nur ein schwimmendes Haus ist, und wenn Sie den Seemann betrachten, der unermessliche Räume durchquert und dabei zusammengezogen und unbeweglich (immobile) in einer recht engen Umfriedung lebt, dann sehen Sie ihn, wie er auf einer Planke die Welt umrundet ganz so, wie Sie und ich auf unserem Parkett das ganze Universum umrunden. ${ }^{16}$

Wir haben es hier mit einer der berühmtesten Formulierungen des französischen Philosophen zu tun - und zugleich einer der spitzfindigsten, welche die physische Bewegung des Reisenden mit den Reisebewegungen eines Lesepublikums korreliert, das seinen Reiseberichten mit den Augen folgt. In dieser Passage ist auf eine andere Weise die Figur des Reisenden und des Lesenden zusammengedacht: Der eigentliche, der wahre Reisende ist nicht derjenige, der sich über die Ozeane und Länder hinwegbewegt, sondern der Reisende, der mit seinen Augen die Berichte aus fernen Welten zu durchdenken und in seinem Kopf eine eigene Welt zu schaffen in der Lage ist. Die wahren Reisenden sind folglich keine anderen als das Lesepublikum, welches gleichsam aus dem Stand die Reisebewegungen mitvollzieht, die es in raschester Abfolge an die verschiedenartigsten Orte und Regionen der Welt führt.

In Diderots Supplément scheint die Figur Bougainvilles die klare Trennung zwischen dem sesshaften und dem reisenden Menschen insoweit zu verwischen, als nun ein dritter Typus eingeführt wird, der in gewisser Weise zwischen beiden Polen zu oszillieren beginnt. Doch wird im Dialog zwischen A und B, welcher der Lektüre des Voyage autour du monde folgt, eben jener Mann, der zweifellos

16 Diderot, Denis: Supplément au Voyage de Bougainville ou Dialogue entre A et B. In (ders.): Oeuvres. Editions établie et annotée par André Billy. Paris: Gallimard 1951, S. 964. 
als der berühmteste und gefeiertste französische Reisende des 18. Jahrhunderts gelten darf, in einer Art „Paradox über den Reisenden“ umgedeutet. Denn dieser Reisende, der nicht reist, wird schließlich mit dem Sesshaften verglichen, der seinerseits Reiseerfahrungen macht, wobei ihm der feste Fußboden seines Hauses zu den schwankenden Schiffsplanken des kontemplativen Reisenden wird. So ist der Leser ein sesshafter Reisender, gleichsam ein sesshafter Lesenomade. Er überquert nicht die Linie (passer la ligne), er folgt vielmehr ihrer Spur beim Lesen quer zu allen Breiten- und Längengraden. Der eigentliche Reisende also ist der Leser - und der Leser ist der im tiefsten Sinne Reisende der europäischen Welt. Denn im Leseakt selbst konkretisiert sich alle Bewegung, läuft sie zusammen. Für den französischen Philosophen steht die Lektüre als gesamtgesellschaftliche Aktivität zentral.

Kommen wir noch einmal auf die angeführte Stelle aus dem neunzehnten Buch zurück, um bei diesem zweiten Durchgang einen zweiten, bislang noch nicht berührten Aspekt zu beleuchten. Glauben wir dem Erzähler, so hinterlässt der Reisende keinerlei Nachkommenschaft: „celui qui voyage ne laisse point de postérité“. Dieser Satz lässt sich nicht nur auf eine familiäre beziehungsweise menschliche, sondern auch auf eine textuelle, ja existentielle und - wie noch zu zeigen sein wird - aktantielle oder handlungsorientierte Nachkommenschaft beziehen. Gehen wir dieser Fährte einmal nach.

Das Frontispiz von Raynals vierbändiger Ausgabe der Histoire von 1780 zeigt uns einen Schriftsteller, dessen Ort des Schreibens in einem Arbeitszimmer situiert ist, in welchem alle Informationen über die außereuropäische Welt gesammelt werden, um schließlich in einen universalistischen Diskurs überführt zu werden, als dessen Zentrum Europa oder die französische Hauptstadt Paris fungiert. Alle Fäden laufen dort zusammen - eine über lange Jahrhunderte in Frankreich jedem Intellektuellen eingepflanzte ,Tatsache‘, deren Allgemeinverbindlichkeit wohl erst in den achtziger Jahren des 20. Jahrhunderts ins Wanken kam.

Die Autorität des Textes ruht also nicht auf der Figur des Reisenden, der die konkrete Wirklichkeit der außereuropäischen Welt aus eigener Erfahrung, aus eigenem Erleben kennt, sondern auf jener des Sammlers von Informationen, mithin des Lesers (und hier macht sich die gemeinsame etymologische Herkunft von Sammeln und Lesen unverkennbar bemerkbar). Der Reisende oder Reise-Schriftsteller produziert als Augenzeuge nur einen provisorischen und prekären Text, den allein der in der Heimat gebliebene Philosoph in all seinen Dimensionen zu verstehen und zu interpretieren vermag. Allein bei diesem hochqualifizierten Leser, der zugleich auch über Textautorität verfügt, liegt die Fähigkeit, alles zusammenzudenken. Hören wir hierzu ein Zitat aus Raynals Histoire des deux Indes von 1781 aus dem siebzehnten Buch: 
Wie lange Zeit doch blieb die Neue Welt sozusagen unbekannt selbst dann, als sie entdeckt worden war? Es oblag nicht barbarischen Soldaten und nicht habgierigen Händlern, gerechte \& vertiefte Vorstellungen über diese Hälfte des Universums zu verbreiten. Einzig die Philosophie sollte von jenen Erkenntnissen profitieren, welche in den Berichten von Reisenden \& Missionaren angelegt waren, um Amerika so zu sehen, wie die Natur den Kontinent gemacht hat \& um jene Beziehungen zu erfassen, die ihn mit dem Rest des Erdballs verbinden. ${ }^{17}$

$\mathrm{Zu}$ Beginn dieses - so die Überschrift - Parallèle de l'ancien et du Nouveau Monde des siebzehnten Buches findet so eine doppelte Bewegung der Enteignung statt. Denn zum einen ist die wahre Entdeckung Amerikas nicht das Verdienst derer, die sich dorthin aufmachten, um diese Welt in Augenschein $\mathrm{zu}$ nehmen und aus eigener Sicht kennenzulernen. Vielmehr ist es das Verdienst jener Menschen, die in der Lage waren, das von den anderen Erblickte und Beschriebene richtig zu interpretieren, indem sie deren Informationen mit anderen Informationen in Beziehung setzten, welche sie über andere Teile des Erdballs gesammelt hatten. Dabei müssen wir selbstverständlich hinzufügen, dass Raynal/Diderot hier lediglich die Soldaten und Conquistadoren, die Missionare und die Händler erwähnt, ohne auch andere Gruppen von Gebildeten miteinzubeziehen, welche die ciudad letrada in der Neuen Welt bevölkerten oder schon zu einem frühen Zeitpunkt Forschungsreisen in die spanischen Kolonien in Amerika unternahmen.

Zum anderen wird diese Deutung der Reiseberichte Dritter wiederum eine Sichtweise, eine Vision Amerikas ,telle que la nature l'a faite“ (so wie die Natur es angelegt hat) ermöglichen. In einer zur ersten analogen Bewegung wurde so die direkte Erfahrung der Neuen Welt, mithin ihre ,Entdeckung' und Wahrnehmung durch reisende Augenzeugen, durch ihre intellektuelle ,Ent-deckung“ ergänzt und mehr noch ersetzt, durch eine Vision, die das Ergebnis einer kritischen Lektüre der verfügbaren Informationen war. Amerika wurde im 18. Jahrhundert in hohem Maße als Textualität, und zugleich distant von Europa aus wahrgenommen sowie als Text gelesen. An die Stelle des Reisens trat nicht allein im philosophischen Diskurs ganz selbstverständlichz das Lesen, die Lektüre.

Denn in diesem Diskurs, wie ihn etwa ein Diderot, aber auch die Autoren von großen Werken über die Neue Welt wie Robertson, de Pauw oder Raynal vertraten, vermochte allein der Philosoph als Instanz einer quellenkritischen Lektüre in Wert zu setzen, was die Reisenden oder die Missionare vor Ort in ihrer Beschränktheit bestenfalls teilweise sehen und erfassen konnten. Fortan kam den Texten von Reisenden und Augenzeugen nur ein sekundärer epistemischer

17 Raynal, Guillaume-Thomas: Histoire, XVII, S. 201f. 
Wert zu, sie blieben - um die Metaphorik des Erzählers zu verwenden - nichts anderes als lumières semées, ein ausgesätes Funkeln, welches allein die Philosophie in ein unter den Menschen verbreitetes Licht umzuwandeln fähig sein konnte. Im Disput zwischen den Reisenden und den Daheimgebliebenen gewannen die letzteren bezüglich der Legitimation ihrer Diskurse und Aussagen deutlich die Oberhand.

Denn allein auf diese Weise und kraft einer kritischen Lektüre konnte aus dem von den Reisenden ,spontan‘ und eher zufällig Gesäten doch noch Fruchtbares entstehen, wobei die textuelle Dimension dieser Fruchtbarkeit dem Leser vor Augen stehen musste. Wir können unschwer erkennen: Das Weltbuch tritt an die Stelle des Buches der Welt. Die Entzifferung der Phänomene ist in erster Linie ein Entziffern einer in Schrift verwandelten Welt, die im Abendland über eine lange Tradition verfügt. Denn ganz im Sinne von Hans Blumenberg ist die Lesbarkeit der Welt nicht mehr vorrangig als Gottes Schöpfung, wohl aber als eine vom Menschen lesbare Natur die Grundlage aller Erkenntnis und besitzt einen deutlichen Vorrang vor einer experimentellen Erforschung von Welt und Umwelt. Das von Hans Blumenberg stammende Eingangszitat zu unserer Vorlesung gibt die Richtung dieser langen, seit der Antike bestehenden Tradition einer Lesbarkeit der Welt vor.

Die Umformung und Veredelung des Rohstoffes der zumeist europäischen Texte - also der Reiseberichte und anderer Informationen - in philosophisch abgesicherte Schriften, die würdig sind, eine Nachkommenschaft $\mathrm{zu}$ zeugen, wird nur unter der Maßgabe einer globalisierenden Lektüre möglich, welche die Beziehungen und wechselseitigen Abhängigkeiten zwischen den von den Reisenden gesammelten Daten und der Gesamtheit des Universums aufzeigt und ins Bewusstsein der Leserschaft hebt. Nicht die experimentelle Erfahrung von Details und Aspekten, sondern die universale Betrachtung aus philosophischer Sichtweise zählte im 18. Jahrhundert. Es verwundert mithin nicht, dass sich Raynals Histoire des deux Indes ganz am Ende ihres Parcours auf andere Lektüren und andere Schreibformen hin öffnet, die ihr eine Nachkommenschaft jenseits der Lebensdauer des Erzählers und Philosophen ermöglichen:

Mögen von der Natur weit mehr begünstigte Schriftsteller mit ihren Meisterwerken vollenden, was ich mit meinen Versuchen begonnen! Möge sich unter den Auspizien der Philosophie eines Tages von einem Ende der Erde bis zum anderen jene Kette des Zusammenhalts \& der Wohltaten sich verbreiten, welche alle zivilisierten Nationen einander weiter annähern sollte! Mögen sie den wilden Nationen nicht länger das Beispiel für lasterhaftes Verhalten \& von Unterdrückung bieten! Ich schmeichle mir nicht, dass mein Name in der Epoche dieser glücklichen Revolution noch lebendig sein könnte. Das vorliegende schwache Werk, welches lediglich das Verdienst besitzt, dereinst weit bessere Werke hervorgebracht $\mathrm{zu}$ haben, wird ohne jeden Zweifel in Vergessenheit geraten sein. Zumindest aber werde ich 
mir sagen können: Ich habe in dem Maße, wie es in meinen Kräften stand, dazu beigetragen, das Glück meiner Mitmenschen zu vergrößern \& vielleicht von weither die Verbesserung ihres Schicksal befördert zu haben. ${ }^{18}$

Nichts vermag hier die Kraft des geschriebenen Wortes, die Stärke der schriftlich verbreiteten Ideen aufzuhalten in einer Bewegung, die zu immer größeren Höhen der Erkenntnis und der literarischen Form hinaufführt. Das Fortschreiten der Menschheit auf diesem Weg zivilisatorischer Verbesserungen im Wechselspiel von Schreiben und Lesen scheint unaufhaltsam: Die Zukunft hält die Befreiung der Menschheit bereit! In dieser Passage ist die weltverändernde Kraft des Buches - und insbesondere der Lektüre - nicht weniger spürbar als eine weitere Dimension von Schriftlichkeit und Buchkultur: Die Literatur ermöglicht ein Weiterleben nach dem Tode, verkörpert insoweit ein Überlebenswissen, insofern es dem Schriftsteller, dem Auctor gewährt, auch noch folgenden Generationen buchstäblich vor Augen zu stehen: als Vor-Bild, als ein literarisches Modell, das stets auf dem Sprung zur Lebenspraxis ist. Der philosophische und literarische Autor wird somit weit über sein eigenes Leben hinaus zum Garanten des Fortschritts der gesamten Menschheit.

Die Aufgabe des Erzählers - und dies betrifft sein literarisch-ideengeschichtliches ,Nachleben` - kann nur mit Hilfe einer Kette von Lektüren erfüllt werden, die ihrerseits zu jenen Meisterwerken hinführen, welche dereinst im Zeichen der Philosophie entstehen werden. Der Erzähler strebt also nicht nach einer Vervollkommnung seines Textes vermittels einer direkten Erfahrung und Recherche oder gar Feldforschung vor Ort, um so die Ausgangsbasis seiner Arbeit über die koloniale Expansion Europas kontrollieren und korrigieren zu können. Von einer derartigen Kontrolle ist sein Denken meilenweit entfernt. In seinen Augen verdankt sich eine solche Korrektur oder Verbesserung keineswegs einer wissenschaftlichen Reise, sondern vielmehr einer Textarbeit, die in der Lage wäre, „diese Geistesschärfe, welche die Mittel in Anschlag bringt, \& jene Beredsamkeit, welche die Wahrheiten zu überzeugen vermag“, ${ }^{19}$ zum Ausdruck zu bringen. Verbesserungen und Korrekturen sind folglich nicht von einer wie auch immer gearteten empirischen, experimentellen Feldforschung, sondern einzig von einer vertieften schriftstellerischen Arbeit zu erwarten.

Wir haben es im Grunde mit einer philologischen Arbeit zu tun. Denn erst die aufmerksame Lektüre erlaubt dem sesshaften Menschen (aber nicht dem „faiseur d'expériences“), seine Mission im Dienste der Menschheit zu erfüllen.

18 Raynal, Guillaume-Thomas: Histoire, XIX, S. 291.

19 Ebd., S. 291. 
Die Lektüre wird als kulturelle Technik - Geistesschärfe und Beredsamkeit sind die beiden durch relecture und réécriture zu erzielenden Hauptqualitäten - vor allem in ihrer sozialen Funktion und Bedeutung hervorgehoben:

Der Handel mit den Erkenntnissen ist für den Gewerbfleiß notwendig geworden, \& es ist alleine die Literatur, welche diese Verbindung herstellen kann. Die Lektüre etwa einer Reise um die Welt vermochte derartige Versuche auszulösen: Denn das Interesse allein führt noch nicht dazu, die Mittel für eine solche Unternehmung zu entdecken. Heutzutage kann man nichts anbauen ohne irgendwelche Studien, ohne irgendwelche Kenntnisse, welche durch die Lektüre vermittelt $\&$ verbreitet wurden. ${ }^{20}$

Die Lektüre und das Lesen sind jene Kulturtechniken, welche eine Gesellschaft überhaupt erst miteinander verbinden, in Kommunikation halten und jegliche Form des Handelns und der Aktivität unterstützen. Ohne ständige Lektüren ist für Raynal wie auch für Diderot weder eine Gesellschaft noch eine Gemeinschaft vorstellbar. Innerhalb eines derartigen Verständnisses erfüllt die Literatur eine kommunikative Funktion, die in gewisser Weise die gesellschaftliche Totalität erst schafft, indem sie das Wissen in alle Zweige und Verästelungen des gesamten sozialen Organismus trägt. Das Lesen bildet gleichsam den Mörtel, der eine Gesellschaft überhaupt erst zusammen und am Leben hält.

Doch die Reichweite von Lesen und Literatur geht in einer europäischen Gesellschaft der Aufklärung, der Lumières, ja in einem Europa mitten in der zweiten Phase beschleunigter Globalisierung, noch wesentlich weiter. Daher wird die Feststellung auch nicht überraschen, dass die Literatur für die textorganisierende Erzählinstanz künftig ein „empire“ darstellt, das die „république Européenne“ vorbereitet: „Das Licht der Aufklärung gewinnt indessen unmerklich einen weiteren Horizont. Eine Art von Reich hat sich sich herausgebildet, das Reich der Litratur, welches die europäische Republik anvisiert und vorbereitet." ${ }^{21}$ So sind es die Literatur und das Lesen, welche in den Augen der französischen Aufklärer eine supranationale Vereinigung und Republik heraufzuführen vermögen, die eine wahrhaft europäische Republik sein werde. Die nicht allein nationale, sondern internationale und die verschiedenen Völker Europas verbindende Literatur übernimmt in diesen Gedankengängen also eine eminent politische und verbindende, gesellschaftsbildende Funktion. Die künftige Gesellschaft werde ein Reich der Literatur, ein Reich der Lektüre sein.

In diesem Sinne besitzt die Literatur (und mit ihr die Lektüre) eine zugleich kommunikative, gesellschaftsbildende und synthetisierende Kraft, die es für die

20 Ebd., S. 269.

21 Raynal, Guillaume-Thomas: Histoire, XIX, S. 268. 
Philosophen der Aufklärung zu lenken gelte. Eine derart utilitaristische Konzeption der Literatur ist aufs Engste verbunden mit einem Verständnis von Wissen, wie es das Gemeinschaftswerk der Encyclopédie unterbreitet hatte. Die Literatur wie auch die Encyclopédie selbst sollten ein Werk zum Nutzen und Fortschritt der Gesellschaft sein. Innerhalb eines solchen Systems, das auf einer revolutionären Ausweitung dessen beruht, was wert ist, einem nicht-spezialisierten Publikum präsentiert $\mathrm{zu}$ werden und ihm bekannt $\mathrm{zu}$ sein, beschränkt sich das Wissen keineswegs auf die traditionellen Wissensbestände der Gebildeten. Zusammen mit einer Ausweitung des Lesens und der Lektüre erfolgt auch eine signifikante Erweiterung der Inhalte des Wissenswerten.

Dieses neugefasste Wissen und seine verschiedenen Bereiche schließen nunmehr grundlegend technische Kenntnisse wie das savoir faire der Handwerker mit ein, ein Wissen also, das über die gesamte Gesellschaft verstreut ist und von der Literatur her über die Lektüre allen interessierten Lesern zugänglich gemacht werden kann. Wir haben es hier ohne jeden Zweifel mit der Fähigkeit der Literatur zu tun, als interaktiver Speicher von Lebenswissen in das Leben selbst einzugreifen und damit eine soziale Praxis zu begründen, gesellschaftliche Strukturen zu verändern.

Von den zahlreichen Argumenten des Erzählers sei nur das folgende hier aufgeführt:

Die Künste zu begünstigen \& die Landwirtschaft zu vernachlässigen, das ist nichts anderes als die Steine in den Fundamenten einer Pyramide zu entfernen, um deren Spitze auszubauen. Die mechanischen Künste ziehen genügend Arbeiter an wegen der Reichtümer, die sie den Unternehmern verschaffen, durch die angenehmen Umstände, welche sie den Arbeitern ermöglichen, durch die Freiheiten, Vergnügen \& Annehmlichkeiten, welche in den Städten entstehen, wo sich die Akteure des Gewerbfleißes treffen. ${ }^{22}$

Geht man von einer derartigen Aufgabenbestimmung der Literatur aus, dann versteht man leicht die wirtschaftliche, soziale, philosophische und politische Wichtigkeit der Lektüre wie auch des Gesamtprojekts der Histoire philosophique et politique des établissements et du commerce des Européens dans les deux Indes. Denn die Literatur zielt dann auf ein pragmatisches Lebenswissen, das zum Vorteil der Künste und der entstehenden Industrie genutzt werden kann.

Aber die Lektüre kann noch weitaus mehr und entfaltet ihre Macht auch auf anderen Gebieten. Denn zur politischen, wirtschaftlichen, gesellschaftlichen und kommunikativen Bedeutung der Lektüre tritt ihre unbestrittene Macht über die Menschen. So ist es - zu einem Zeitpunkt, als Frankreich seine Anstrengun-

22 Raynal, Guillaume-Thomas: Histoire, XIX, S. $180 f$. 
gen $\mathrm{zu}$ bündeln versuchte, um die Vormachtstellung der Briten als Seemacht wenn nicht $\mathrm{zu}$ brechen, so doch zumindest in die Schranken zu weisen - gerade die Lektüre einer Weltumsegelung, die ihre große Ausstrahlungskraft auf die Geister jener Zeit entfaltet und eine unmittelbare Anwendung des Erlebens des Lesers auf eine vitale und handlungsorientierte Erfahrung lenkt. Das Lesen zielt in der Histoire des deux Indes auf das Handeln, es zielt auf Macht über Menschen und deren Aktivitäten und versucht, diese in ganz bestimmte Richtungen $\mathrm{zu}$ lenken.

So ist Lesen daher paradoxerweise mehr als Reisen, bedeutet es doch, an einer gesellschaftlichen Verbreitung eines präzise umrissenen Wissens (nämlich der Erfahrung eines konkreten Reisenden) teilzuhaben, um diese neuen Wissensbestände in den Dienst aller zu stellen und künftig neue Reisen zu stimulieren. Die Lektüre eines Reiseberichts ist gleichbedeutend mit dem Nacherleben dieser Reise, ein Erleben, das von einer großen Leserschaft in relativ kurzer Zeit geteilt und weiter verbreitet werden kann. Auf diese Weise können die verschiedenen Wissenstypen und -bereiche vermittels der Literatur und der Lektüre - und stets im Zeichen der Philosophie - miteinander in Beziehung gesetzt und ausgetauscht werden, um neue Gebiete abzustecken und zu erobern.

Daraus erhellt sich die ganze Tragweite und Bedeutung dieser Kulturtechnik ebenso für Epistemologie und Genese der Histoire des deux Indes wie für deren Verbreitung und gesellschaftliche Wirkkraft. Es lohnt sich zu fragen, auf welche Weise dieser Text seinen Leser bildet, ihn informiert und zugleich umformt. Denn die Histoire des deux Indes ist nicht nur eine Encyclopédie der kolonialen Expansion Europas über die Welt, sie ist zugleich auch eine Kritik vieler kolonialer Praktiken, die es abzustellen gelte. Sie ist keineswegs eine Verurteilung des europäischen Kolonialismus in toto, wohl aber ein Versuch, diesen Kolonialismus in rationale Bahnen $\mathrm{zu}$ lenken - ein durchaus zweischneidiges und in sich widersprüchliches Unternehmen.

Es geht in unseren Überlegungen weder um eine neuerliche Analyse der verschiedenen Lesarten des Raynal'schen Hauptwerkes noch um eine Untersuchung der Lektüren Raynals und seiner zahlreichen Mitarbeiter, die zu diesem Kollektivwerk von enzyklopädischem Anspruch beigetragen haben. Vielmehr konzentrieren wir uns in diesem Teil unserer Vorlesung ganz auf die Kraft der Kulturtechnik des Lesens, seine gesellschaftliche Funktion und die Wirkung der Lektüre in einem Europa der Aufklärung, das erstmals eine ,öffentliche Meinung sich allenthalben entwickeln sah. Versuchen wir folglich, noch besser zu verstehen, wie Lektüre und Leser in der Histoire des deux Indes präsentiert werden, auf welche Weise die Lektüre in Szene gesetzt wird und wie dieser Bestseller der Lumières es unternimmt, die Aktivitäten und das konkrete gesellschaftliche 
Handeln seiner Leser zu stimulieren und zu kanalisieren, indem der Leserschaft bestimmte Lektüremodelle angeboten werden.

Beginnen wir mit unseren Überlegungen bei einer Anekdote, die einen historischen Leseakt und dessen Bestrafung zeigt. Glaubt man einer in den nouvelles à la main kolportierten Szene, die Linguet in einer Besprechung des Raynal'schen Werkes für die Annales wiederaufnahm, dann wurde ein höherer Offizier der spanischen Kriegsmarine in Havanna dazu verurteilt, „öffentliche Abbitte zu leisten vor einer großen Menschenmenge, die in der Hauptstadt dieser spanischen Insel versammelt war, gegenüber Gott und der ,Heiligen Inquisition““, weil er in seiner Kabine eine Passage aus der Histoire des deux Indes still und heimlich gelesen hatte. ${ }^{23}$ Lesen war also alles andere als unschuldig. Denn die Lektüre eines Buches, das auf bisweilen heftigste Weise religiöse Despotie und Intoleranz im Allgemeinen und die spanische Inquisition im Besonderen anprangerte, brachte gewisse Gefahren mit sich, und zwar nicht nur für jenen, der seine Autorschaft ,zugab، und Verfolgungen bis hin zur Exilierung ausgesetzt war, sondern auch zumindest in bestimmten Ländern - für jene, deren Lektüre des Werkes (und erfolgte sie auch im stillen Kämmerlein) öffentlich bekannt wurde. Denn die Leser gesellschaftsverändernder, aufrührerischer Schriften konnten im Namen der herrschenden Macht belangt werden.

Überall machten sich in der Epoche der Aufklärung Menschen als Leser verdächtig. Denn jedweder Leser konnte ein virtueller Komplize des Autors sein, oder sich zumindest mit diesem solidarisch erklären: Die Leser steckten gleichsam mit ihren Autoren unter einer Decke. Daher überrascht die Feststellung nicht, dass die Histoire des deux Indes selbst eine derartige Lektüresituation enthält, wobei der Erzähler selbstverständlich nicht umhinkommt, die Bedeutung schriftlicher Kommunikation als Gegen-Macht ironisch und gleichsam nebenbei ins rechte Licht zu rücken. Lesen wir also kurz diese in der Kolonialenzyklopädie selbst in Szene gesetzte Lese- und Konfrontationssituation, da sie uns einiges über die erhofften Lektüreprozesse mitteilen kann:

Man kann die Fortschritte der Aufklärung mitnichten aufhalten; man kann sie lediglich zu eigenen Ungunsten verzögern. Denn das Verbot irritiert nur \& lässt in den Seelen das Gefühl einer Revolte entstehen \& verleiht dem Werk den Ton eines Pamphlets; und man erweist unschuldigen Subjekten zuviel Ehre, wenn man unter seinem Befehl zweihunderttausend Mörder hat \& dabei wenige Seiten Schrift so sehr fürchtet. ${ }^{24}$

23 Die Anekdote findet sich auch bei Guénot, Hervé: La réception de l'Histoire des deux Indes dans la presse d'expression française (1771-1781). In: Lüsebrink, Hans-Jürgen / Tietz, Manfred (Hg.): Lectures de Raynal, S. 76.

24 Raynal, Guillaume-Thomas: Histoire, X, S. 203. 
Die Lektüre ist ein potenziell gesellschaftsverändernder Prozess, der von allen Herrschenden gefürchtet wird, könnte er doch die etablierte Ordnung in Gefahr bringen. Die Histoire des deux Indes weist eine Vielzahl von Situationen auf, die auf einer oft schweigenden Solidarität zwischen explizitem Autor und explizitem Leser beruhen. Das „sentiment de révolte“ wird von beiden geteilt.

Es wäre gleichwohl unzutreffend, die Beziehungen zwischen den verschiedenen Autor- und Leserfiguren stets im Sinne eines gemeinsamen Kampfes zugunsten von Fortschritt und Aufklärung zu begreifen. Denn die Inszenierungen von Lektüreprozessen in der Histoire des deux Indes sind weitaus differenzierter zu sehen. Die komplexe Choreographie der wechselseitigen Beziehungen zwischen den expliziten Figuren Autor und Leser bildet nicht immer einen gemeinsamen affektiven Raum, wie er fraglos in einigen der bislang analysierten Passagen zum Ausdruck kommt. Freilich lässt sich immer wieder eine Inszenierung identischer Meinungen und gemeinsamer Gefühle erkennen, denken wir nur an jene berühmte Stelle, an welcher der an seinem Schreibtisch sitzende Schriftsteller die Feder nicht mehr weiterzuführen vermag, da ihm bei der Schilderung des von den Spaniern - jener „race d'exterminateurs“, wie Bolivar sie 1815 nennen sollte - an den Indianern verübten Genozids Tränen in die Augen treten:

Ihre Rasse ist nicht mehr. Ich muss einen Augenblick innehalten. Meine Augen füllen sich mit Tränen \& ich sehe nicht mehr, was ich schreibe. ${ }^{25}$

An verschiedenen Stellen der Geschichte beider Indien muss der Schriftsteller warten und innehalten, bis seine Tränen wieder getrocknet sind, um im Anschluss wüste Vorwürfe und Beschimpfungen der Mörder aus seiner Feder auszuschütten. Aber dieses tränenreiche Verfahren ist ansteckend und gibt gleichsam die Lektüreanweisung für ein Lesepublikum, das emotional mitgerissen werden soll und in der Tat auch mitgerissen wurde - wie viele Rezeptionszeugnisse zeigen. Auch der wohlmeinende Leser wird bei der Lektüre der schrecklichen Szenerien von Unterwerfung und Kolonisierung der außereuropäischen Welt die Tränen angesichts der unzähligen Grausamkeiten nicht zu unterdrücken vermögen. Die unmittelbare Kommunikation zwischen ,Autor`/ Erzähler und ,Leser' kommt hier in einer analogen und symmetrischen Bewegung zum Ausdruck, die alle Spuren einer (gleichwohl fiktiven) mündlichen und kopräsenten Kommunikationssituation trägt. So weint im sechsten Buch endlich auch der Leser ganz explizit:

25 Ebd., VI, S. 223. 
Sind Sie böse? Oder sind Sie gut? Sind Sie gut, so würden Sie, wie mir scheint, den Bericht all dieser Kalamitäten zurückweisen; sind Sie aber böse, so würden Sie verstehen, ohne dabei zu weinen. Aber halt, Sie weinen. ${ }^{26}$

Ist er nun gut oder ist er böse, der Leser der Histoire des deux Indes? Zu unserer Beruhigung haben wir es hier - die Heulprobe belegt es - mit dem guten, dem wohlmeinenden Lesertypus zu tun. Der Autor ist folglich im Einklang mit seinem Lesepublikum. Und das Lesepublikum ist gerührt von all jenen Gräueltaten, die ihm vom Verfasser der Geschichte beider Indien erzählt wurden.

Die Beziehungen zwischen expliziter Autor- und Leserfigur beschränken sich in der Histoire des deux Indes jedoch nicht auf dieses Grundmuster. Greifen wir auf die von Roland Barthes in seinen Fragments d'un discours amoureux verwendete Terminologie zurück, so könnten wir mit einigem Recht von verschiedenen Figuren sprechen, welche die von der écriture Raynals und Diderots inszenierte textinterne Kommunikation rhythmisieren. Es sind Figuren, figurae, im vollen Wortsinne - und der reale Autor spielt mit ihnen und spielt mit uns. Die Histoire des deux Indes enthält bekanntlich zahlreiche direkte Ansprachen an den Leser, die zweifellos wesentlich zum großen Erfolg des Textes beim Publikum des 18. Jahrhunderts beigetragen haben. Diese direkte Kommunikation zwischen ,Autor' und ,Leserschaft‘ ist von großer Tragweite und soll nunmehr näher untersucht werden, um besser $\mathrm{zu}$ verstehen, wie die Geschichte beider Indien seit ihrem erstmaligen Erscheinen zu einem solch Furore machenden Bestseller werden konnte. Es geht mir also im Folgenden um die Figuren der Leser und um die Figuren des Lesens.

Von jeher haben die in der Geschichte beider Indien so prominent positionierten „appels au lecteur“ das Interesse der Forschung auf sich gezogen. ${ }^{27}$ In diesen über den gesamten Verlauf der Histoire des deux Indes gestreuten Appellen wendet sich der Erzähler als Redner an sehr unterschiedliche Leser, wodurch ein virtueller öffentlicher Raum entsteht. Dieser öffentliche Raum schließt ebenso Unterdrückte wie Unterdrücker, ebenso manches gekrönte europäische Haupt (wie etwa in der berühmt gewordenen Wendung an Friedrich II. im vierzehnten Buch) wie auch die anonymen Sklaven Nordamerikas mit ein. Es war gerade die spannungsvolle Heterogenität dieses Raumes, welche von jeher die Leser der Kolonialenzyklopädie fesselte und zugleich virtuell eine Öffentlichkeit herstellte, in der Täter wie Opfer miteinbezogen wurden.

26 Ebd., S. 323.

27 Exemplarisch sei hier verwiesen auf die schöne Studie von Delon, Michel: L'appel au lecteur dans l'Histoire des deux Indes. In: Lüsebrink, Hans-Jürgen / Tietz, Manfred (Hg.): Lectures de Raynal, S. 53-66. 
Doch dieser Raum der Geschichte beider Indien ist noch weiter. Denn bisweilen wendet sich der Erzähler in einer Art entsakralisiertem Gebet unmittelbar an Gott, um sich anschließend den Kolonisatoren zuzuwenden, die die noch unbestellten Felder der Neuen Welt erschließen. Die Vielfalt unterschiedlichster expliziter Adressaten gestaltet einen Kommunikationsraum innerhalb der Histoire des deux Indes, den es freilich nicht mit dem realen Wirkungskreis des Raynal'schen Werkes zu verwechseln gilt. Beide Bereiche sind klar voneinander getrennt. Doch handelt es sich um einen Interaktionsraum, der als Modell für die Beziehungen zwischen dem Autor und seinem Text einerseits, dem Leser und dessen Reaktionen andererseits fungiert und somit Leseprozesse modelliert und simuliert. Vor diesem Hintergrund ist überaus bedeutsam, dass die Erzählerinstanz gezwungen ist, gewisse Leser auszuschließen, um einen mehr oder minder klar umrissenen öffentlichen Raum zu schaffen. Denn es gibt - wie wir schon im obigen Zitat sahen - auch böse Leser. In diesen Fällen tritt die Figur des Bruchs an die Stelle jener der Solidarität, welche freilich stets den ,Normalfall` der Kommunikation darstellt.

Diese Überlegungen seien anhand eines Beispiels kurz verdeutlicht. Als der Erzähler zu einem bestimmten Zeitpunkt von einem Leser, der nur nach Informationen über Reichtümer in den zu kolonisierenden Gebieten der Neuen Welt verlangt, direkt angesprochen wird, fällt seine Antwort wie folgt aus:

\footnotetext{
Wer auch immer Du sein magst, der mich so herausforderst, Du habgieriger Mensch, Du geschmackloser Mensch, der Du einmal nach Mexico \& nach Peru verbracht weder die Sitten noch die Gewohnheiten der Menschen studieren würdest [...]; ich sehe, dass Du in die Lektüre meines Werkes eingefallen bist ganz wie die grausamen Europäer in diese reichen \& unglücklichen Gebiete; ich sehe, dass Du würdig wärest, diese zu begleiten, weil Du dieselbe Seele wie sie besitzst. Nun gut, steige in diese Bergbaustollen hinab; und finde dort den Tod an der Seite jener, die sie für Dich ausbeuten; \& solltest Du wieder an die Erdoberfläche hinaufsteigen, so erkenne zumindest die verbrecherische Quelle dieser finsteren Schätze, auf die Du es abgesehen hast; mögest Du sie niemals besitzen, ohne doch alle Skrupel zu empfinden. Möge das Gold seine Farbe wechseln \& Deine Augen es nur in Blut getaucht erblicken. ${ }^{28}$
}

Dies ist ein herrlicher Fall aufklärerischer Publikumsbeschimpfung! Denn wir haben es hier mit einer kleinen, für den bösen Leser reservierten textinternen Hölle zu tun, in welche der bösartige Ausbeuter verstoßen wird, da er sich nur für Daten der Geschichte beider Indien interessiert, die seinen egoistischen Plänen zu nutzen vermögen. Zur Hölle mit ihm!

28 Raynal, Guillaume-Thomas: Histoire, VII, S. $117 \mathrm{f}$. 
Es handelt sich um einen direkten Angriff auf einen bestimmten Lesertypus, den es historisch sehr wohl gab und der alles andere als selten war. Der hier von einem entrüsteten Erzähler apostrophierte habgierige Leser verlangt ohne Umschweife nach einem Text, der für Lesarten pragmatischen Zuschnitts gemacht ist. Und genau an solchen Daten und Fakten war ein nicht geringer Teil der Leserschaft der Geschichte beider Indien durchaus interessiert. Diesem Interesse entsprachen spezifische Editionen, welche genau auf derartige Angaben abzielten und viele andere, bloß philosophische Überlegungen ausklammerten. Denn das wohlkalkulierte Interesse an möglichst belastbaren Informationen und Fakten über die Kolonialgebiete war in europäischen Kreisen gewaltig. Dem aber wird zumindest rhetorisch ein Riegel vorgeschoben.

Wir haben es hier mit dem plündernden Leser zu tun, gegen den sich auch Nietzsche so vehement verwahrte, jener Leser, der aus einem Text nur das herausholt, was er selber gerade gut gebrauchen kann, ohne sich um den gesamten Text und dessen Bedeutungsebenen zu kümmern. Eine derart pragmatische Lesart würde es diesem Lesertypus erlauben, das in der Kolonialenzyklopädie angehäufte Wissen in einem Sinne zu instrumentalisieren, der den vom Erzähler affichierten Absichten diamentral entgegengesetzt ist.

Wir wissen heute, dass die Histoire des deux Indes einer solchermaßen pragmatischen und fragmentarischen Lektüre in der Tat des Öfteren unterzogen wurde, und dass es sich bei dieser Leserschaft in erster Linie um Gruppen und Gesellschaften handelte, die am internationalen Handel beziehungsweise der gezielten Ausbeutung des materiellen Reichtums der Kolonialländer sehr gut verdienten. ${ }^{29}$ Gewiss, diese Lesart blieb nicht auf die Leser der Geschichte beider Indien beschränkt, sondern erfasste selbst das Werk eines so kolonialismuskritischen Reisenden wie Alexander von Humboldt. ${ }^{30}$ Doch sie war bei Raynal auch und gerade bezüglich der Übersetzungen seiner Histoire des deux Indes in verschiedene europäische Sprachen sehr ausgeprägt.

Es ist aufschlussreich, dass die zentralisierende Erzählerinstanz der Histoire des deux Indes, die ähnlich wie die Encyclopédie das Ergebnis einer kollektiven

29 Vgl. hierzu u. a. Lüsebrink, Hans Jürgen: Die „Geschichte beider Indien“ - ein verdrängter Bestseller. In: Raynal, Guillaume / Diderot, Denis: Die Geschichte beider Indien. Ausgewählt und erläutert von Hans-Jürgen Lüsebrink. Nördlingen: Franz Greno Verlag 1988, S. 329-347.

30 Vgl. Ette, Ottmar: „Unser Welteroberer“: Alexander von Humboldt, der zweite Entdecker, und die zweite Eroberung Amerikas. In: Amerika: 1492-1992. Neue Welten - Neue Wirklichkeiten. Essays. Herausgegeben vom Ibero-Amerikanischen Institut Preußischer Kulturbesitz und dem Museum für Völkerkunde Staatliche Museen zu Berlin. Braunschweig: Westermann 1992, S. 130-139. 
Anstrengung war und sich durch eine fragmentarische Schreibweise ${ }^{31}$ auszeichnet, den Versuch einer derartigen Aneignung und Instrumentalisierung durch den häufig wiederholten Hinweis auf eine notwendig umfassende und kontinuierliche Lektüre zu unterbinden sucht. Gegen die Interessen einer real existierenden Leserschaft freilich konnte dies wenig mehr sein als ein rhetorisches Hilfsmittel, das die bonne foi der an der Abfassung des Werkes beteiligten französischen Philosophen unterstrich.

Wir haben es in diesen Interaktionen nicht mehr mit der Figur einer geistigen und moralischen Solidarität zwischen explizitem Autor und explizitem Leser zu tun. Es ist vielmehr zu einem Bruch gekommen. Die Wünsche des Erzählers begleiten den habgierigen Menschen, dessen Laster gerade nicht die Lesegier ist, auf dessen Weg in die nach kolonialem Vorbild arrangierte Hölle. So finden die Missetaten eine ihnen angemessene Art der Bestrafung. Der europäische Ausbeuter steigt in die Schächte und Minen hinab, die seit dem 16. Jahrhundert, seit den europaweit vernommenen Klagen des Bartolomé de las Casas, zum Symbol von Ausbeutung und Genozid an den Indianern geworden waren. Doch noch immer triumphiert die Habgier des europäischen Kolonialismus, die hier in ihrer menschenverachtenden Grausamkeit vom Erzähler angeprangert wird. Wir wohnen geradezu der Hinrichtung einer expliziten Leserfigur bei, die nach Aussage des Erzählers in seinen Text so eingedrungen ist, wie es die „féroces européens“ in den amerikanischen Kolonien taten. Doch das Lesen und Sammeln von Daten und Informationen ist ein nicht vom Autor oder vom Erzähler zu kontrollierender Prozess.

Die vom Erzähler gezogene Parallele zwischen Kolonie und Kolonialenzyklopädie entbehrt nicht des Interesses. Ein Leser, der zum Zwecke der Ausbeutung in die Tiefen der Bände der Histoire eingedrungen wäre, hätte zugleich den legitimen Besitzer dieser Reichtümer in einen Sklaven verwandelt, der stets von Verfolgung und Mord bedroht wäre. Wir hätten es folglich mit einer kolonisierenden Lektüre zu tun, welche die in jahrelanger Arbeit gesammelten und aufgehäuften Reichtümer der Geschichte beider Indien wohl verstanden, sich aber nur zur Verfolgung eigener Ziele angeeignet hätte. Dergestalt würde die Histoire des deux Indes auf der Ebene der Lektüre mit ihrem Gegenstand, den Kolonien, verschmelzen und deren Ausbeutung durch mächtige Nationen und Gesellschaften Europas noch beschleunigen. Die pragmatische Lesart erscheint daher als eine kolonialistische Lektüreweise.

31 Vgl. hierzu die frühe und verdienstvolle Untersuchung der Beziehungen zwischen Diderot und dem Raynal'schen Werk von Duchet, Michèle: Diderot et l'Histoire des Deux Indes ou l'écriture fragmentaire. Paris: Nizet 1978. 
So präsentiert uns die Figur der Enteignung und Kolonisierung von Text und Autor, die der bereits dargestellten Figur der Solidarität entgegengesetzt ist, ein (Lese-)Modell, das auf einer grundlegenden Instrumentalisierung, aber auch auf einer fundamentalen Ungleichheit beruht. Auch ein solcher, auf den ersten Blick rein pragmatischer lector in fabula würde einen auf ein konkretes Handeln abgestellten Lektüretyp verkörpern, doch würden der Autor und sein Text zu dessen ersten Opfern. Der ohnehin fragmentarische Text würde wie in einer Goldmine in kleine und feinste Teilchen zerstückelt, um noch besser und effizienter im Sinne einer buchhalterischen Auflistung lohnenswerter Objekte der Ausbeutung der Kolonien und ihrer Bewohner durch die Europäer dienstbar gemacht werden zu können. Eine Literatur im Zeichen der Philosophie würde damit ihre gesamte kommunikative, egalitäre und synthetisierende gesellschaftliche Kraft einbüßen. Genau gegen diese Zweckentfremdung wendet sich vehement die zumeist von Denis Diderot gestaltete Erzählerfigur in der Histoire des deux Indes.

Doch bleiben wir noch für einen Augenblick bei der Inszenierung dieser Leseszene! Denn vergessen wir nicht, dass die vom Erzähler verkündete Todesdrohung gleichzeitig die Inszenierung einer Lektüre im Sinne einer Dramatisierung und in erster Linie eine Gerichtsszene ist, bei welcher dem schlechten Leser die Rolle des Angeklagten zukommt, während seinem Richter alle Attribute einer transzendenten Macht zufallen. Die Raynal-Forschung hat im Verlauf der letzten Jahrzehnte die fast obsessive Präsenz eines Erzählers als Geschichtsschreiber und Philosoph herausgearbeitet, dessen absolute Macht das Jüngste Gericht geradezu heraufbeschwört. In seiner luziden Studie über die Herausbildung des Kollektivsingulars der „Geschichte“ als Grundstruktur des Denkens und der Epistemologie am Ende des 18. Jahrhunderts hat Reinhart Koselleck eben diesen Aspekt hervorgehoben. So schrieb er sehr pointiert:

Fast unter der Hand wurde aus der - seit der Antike - richtenden Historiographie eine Historie, die selbsttätig die Richtsprüche vollstreckt. Das Werk von Raynal, nicht zuletzt dank Diderots Nachhilfe, zeugt davon. Das Jüngste Gericht wird seitdem gleichsam verzeitlicht. Die Weltgeschichte ist das Weltgericht. ${ }^{32}$

Nicht von ungefähr kommt es im Verlauf der Histoire des deux Indes zu einer Vielzahl von Gerichtsszenen, welche die Leserschaft bewegt haben dürften. Auch bei diesen Szenen finden wir freilich eine bipolare Struktur vor. Dem Tribunal der Inquisition, dem Symbol absurden Aberglaubens und finsterer Unterdrückung,

32 Vgl. Koselleck, Reinhart: Historia Magistra Vitae. Über die Auflösung des Topos im Horizont neuzeitlich bewegter Geschichte. In (ders.): Vergangene Zukunft. Zur Semantik geschichtlicher Zeiten. Frankfurt am Main: Suhrkamp 21984, S. 64. 
steht das Tribunal der Philosophie (und nicht nur der Geschichtsphilosophie oder der Weltgeschichte) gegenüber. Dieses Tribunal verkörpert die Vernunft und die Moral in sich:

In der Tat ist vor dem Tribunal der Philosophie \& der Vernunft die Moral eine Wissenschaft, deren Ziel die Bewahrung \& das gemeinsame Glück der Menschheit ist. Diesem doppelten Ziele müssen ihre Regeln zugeordnet sein. ${ }^{33}$

Und der Erzähler präzisiert aus dieser Warte eines höheren Wissens und einer im Dienste der gesamten Menschheit stehenden Wissenschaft sogleich als Philosoph:

Es gibt zwei Tribunale, jenes der Natur \& jenes der Gesetze. Das eine kümmert sich um die Vergehen des Menschen gegen seinesgleichen, das andere um die Vergehen des Menschen gegen sich selbst. ${ }^{34}$

Der des Öfteren umfangreich kommentierte Auftritt der Polly Baker (oder „Polli Backer“35) vor ihren Richtern, ein Meisterstück der (literarischen) Gerichtsrede, das wir der Feder Diderots verdanken, könnte sehr wohl als Inszenierung dieses Modells gedeutet werden, wobei das Tribunal der Natur und der Gesetze vom Tribunal der Philosophie versinnbildlicht wird. Es stellt und stemmt sich ganz bewusst jedwedem Geiste der (spanischen) Inquisition entgegen. Innerhalb eines solchen Gedankengebäudes wird der Philosoph zum obersten Richter, der seine Urteile von übergeordneter Warte aus verkündet und damit einen Platz über den Menschen einnimmt, der mit dem eines Gottes der Vernunft vergleichbar wäre. Die Position des Philosophen ist folglich eine übergeordnete Machtposition, von der aus rhetorisch eindrücklich Recht gesprochen wird.

Der virtuelle öffentliche Raum, den die Histoire philosophique et politique des établissements et du commerce des Européens dans les deux Indes konstruiert, ist ein Raum, der von einer doppelten Bewegung der Desakralisierung und Resakralisierung geprägt ist und von der zentralen Figur des Autors, des Schöpfers dieses Werkes, beherrscht wird. Dieser Figur kommen nahezu übermenschliche Attribute zu, welche auch in der Einwirkung des philosophe auf die Leserschaft deutlich zum Ausdruck kommen.

Welche Rolle spielt nun die Lektüre innerhalb einer solchen Theatralisierung der öffentlichen Rede und des öffentlichen Raumes?

33 Raynal, Guillaume-Thomas: Histoire, XIX, S. 272.

34 Ebda., XIX, S. 273.

35 Ebda., XVII, S. $287 \mathrm{f}$. 
Nur auf den ersten Blick scheint man in der Histoire des deux Indes eher wenig zu lesen. Die erwähnte Theatralisierung verleiht dem Text etwas zutiefst Mündliches und zugleich die Leserschaft unmittelbar Herausforderndes. Selbst des realen Autors Lektüre von Bezugstexten wird häufig in öffentliche Rede verwandelt: Wir sehen gleichsam bei der Entstehung des gesamten Werkes durch ein konzentriertes und aktives Lesen zu. Mag es sich um die unterschiedlichen Standpunkte der nordamerikanischen Siedler handeln, die den Raum eines Parlaments schaffen, das die Tyrannei des britischen Mutterlandes verurteilt ${ }^{36}$ - und man könnte hier durchaus von einer Simulation des parlamentarischen Raumes sprechen, der die Voraussetzung für die alles beherrschende Stimme des Philosophen bildet -, oder mag es sich um einander entgegengesetzte Theorien über die Gebirgsbildung ${ }^{37}$ gehen - stellen die Auseinandersetzungen zwischen Plutonisten und Neptunisten doch eine der großen Kontroversen dar, die das gesamte Jahrhundert der Aufklärung in ihren Bann schlugen - : Stets werden die jeweils aufgerufenen Bezugstexte in Reden und dialogische Stellungnahmen umgewandelt. Die dadurch immer wieder erzählte Mündlichkeit sorgt für die Unmittelbarkeit und Direktheit einer Ansprache der Leserschaft, die für den Erfolg des gesamten Werkes zweifellos mitverantwortlich war.

An dieser Stelle ist eine Differenzierung zwischen zwei Kommunikationsräumen, die sich auf der Ebene der Textualität der Histoire des deux Indes voneinander unterscheiden, unumgänglich. Auf der einen Seite lässt sich ein interner Kommunikationsraum ausmachen, der die wechselseitigen Stellungnahmen der unterschiedlichen narrativen Instanzen (wohlgemerkt: mit Ausnahme der des expliziten Lesers) präsentiert und dialogisch aufeinander bezieht. Auf der anderen Seite lässt sich hiervon ein externer Kommunikationsraum abgrenzen, der sich zwischen diesen narrativen Instanzen und den verschiedenen Leserfiguren der Histoire etabliert. Selbstverständlich sind diese beiden Räume (die sich allein auf der textinternen und nicht auf der textexternen Ebene, also zwischen dem realen Autor - Raynal, Diderot usw. - und dem realen Publikum des 18. Jahrhunderts ansiedeln) miteinander kommunizierbar und in der Tat auch eng miteinander verbunden. Gleichwohl stellen sie Räume eigenen Charakters dar, innerhalb derer die Kommunikation in der Geschichte beider Indien jeweils anderen Gesetzmäßigkeiten gehorcht.

Sehen wir uns diese klare Struktur noch einmal etwas näher an. Hinsichtlich des internen Kommunikationsraumes darf man festhalten, dass die Lektüren

36 Vgl. ebd., XVIII, S. $165 \mathrm{ff}$. sowie S. $172 \mathrm{ff}$.

37 Vgl. etwa die „Digression sur la formation des montagnes“ in ebda., VII, S. 88ff. und deren dialogische Struktur. 
Raynals und seiner Mitarbeiter fast immer in mündliche Stellungnahmen und ,Redebeiträge‘ umgewandelt wurden. Dies scheint ein generelles Prinzip der écriture dieses Textes zu sein. So werden etwa die Theorien und Untersuchungen zur Naturgeschichte der beschriebenen Länder oftmals in mündliche Sprache umformuliert und dem Lesepublikum damit näher gebracht. Auf dieser Ebene lassen sich die zahlreichen Widersprüche und stilistischen Brüche ansiedeln, die den Text (zer-)gliedern und ihm vieles von einer durchaus möglichen Kohärenz nehmen.

Zugleich entsteht eine textuelle Heterogenität, für die das Ende des 20. und der Beginn des 21. Jahrhunderts - und dies wäre möglicherweise einer von mehreren Gründen für die ,Wiederentdeckung، der Histoire des deux Indes und mehr noch des Interesses, das sich in den beiden zurückliegenden Jahrzehnten verstärkt bemerkbar gemacht hat - eine spezifische Sensibilität entwickelt hat, die diese Heterogenität als Phänomen offener Textualität zu genießen vermag. Der ,zusammengesetzte‘ Charakter der Geschichte beider Indien stört die heutige Leserschaft nicht länger. Innerhalb dieses internen Kommunikationsraumes stellt das sicherlich bekannteste Werk, das unter dem Namen Raynals veröffentlicht wurde, einen offenen Text im Sinne einer Polyphonie, einer Vielstimmigkeit Bachtin'schen Zuschnitts dar. Die Intertextualität wurde so in eine direkte oder indirekte Interaktion zwischen verschiedenen Stimmen umgewandelt, welche von der zentralisierenden Erzählerfigur mehr oder minder dirigiert, bisweilen aber auch - so scheint es zumindest - ganz ,vergessen' werden. Auch hieraus wird klar, welch herausragende Rolle dieser zentralen Erzählerfigur in der Histoire zukommt.

Wenden wir uns nun dem zweiten Raum zu. Bezüglich des externen Kommunikationsraumes besitzt die Histoire des deux Indes eine bewundernswerte Ambivalenz, von der die dort angesiedelten Lektüreprozesse betroffen sind. Die Wendung des Erzählers - bei größerer Diferenzierung ließe sich sicherlich von mehreren Erzählerfiguren sprechen - an den Leser ist unter Einschluss der bereits erwähnten „appels au lecteur“ häufig von einer mündlichen Grundstruktur geprägt, welche an der Erzeugung von Unmittelbarkeit ausgerichtet ist. Sie richtet sich aber an ein Lesepublikum, dessen Lesetätigkeit unterstrichen wird.

Im Allgemeinen ist die Offenheit des Textes wie der Kommunikationssituation begrenzt. In diesem Kommunikationsraum siedeln sich jene Fragmente an, die - aus der Feder Diderots stammend und sich des Gesamttextes der Histoire gleichsam bedienend - dem Leser einen „discours incendiaire“ entgegenschleudern, der nicht nur die hispanoamerikanischen Leser beeindruckte und gleichsam anfeuerte. In den Passagen eines in Brand setzenden Diskurses wird der Informationen empfangende Brennspiegel seinerseits zum Nachrichten, ja Aufrufe und Proklamationen ausstrahlenden Parabolspiegel umfunktioniert. Auf dieser Ebene entfaltet sich die ganze Gewalt und Kraft der Raynal'schen machine de guerre, die im 18. Jahrhundert so erfolgreich war. 
Derlei Passagen versuchen zumeist, aus den vorangehenden Textteilen nicht nur Schlüsse zu ziehen, sondern den Leser zu konkreten Haltungen und Handlungen zu ermutigen, ja aufzustacheln. Als textinterne Figur wird der Leser in eine aktantielle Instanz verwandelt: Er ist zum Handeln bereit. Seine Reaktionen können affektiv (Tränen), intellektuell (Lektüre als interne Verwandlung des Lesers) oder an konkretem Handeln (Revolte) ausgerichtet sein. Stets handelt es sich um einen aktiven oder besser: um einen aktivierten Leser, der die gesellschaftsverändernde Bühne betritt und sich in die Entwicklungen seiner Epoche vehement einmischt. Wir verstehen daher die Dynamik, welche von der Geschichte beider Indien gerade in den Kolonialgebieten des amerikanischen Kontinents ausging.

Das folgende Beispiel mag den zweiten, zweifellos von der Forschung bislang wenig beachteten Reaktionstyp verdeutlichen und uns dessen Funktionsweise vor Augen führen:

Ihr Europäer, die Ihr so stolz seid auf Eure Regierungen, auf Eure Gesetze, auf Eure Institutionen, auf Eure Monumente, auf all das, was Ihr als Eure Weisheit bezeichnet, erlaubt mir, Euch einen Augenblick aufzuhalten. Ich habe Euch gerade mit Einfachheit \& ohne Kunstfertigkeit ein Gemälde des Lebens \& der Sitten des Wilden vorgelegt. Ich habe Euch weder seine Laster verschwiegen noch seine Tugenden übertrieben. Ich bitte Euch, den Gefühlseindruck, den mein Bericht in Euch ausgelöst hat, in Euch zu bewahren, bis der schönste Geist, der beredsamste Mensch unter Euch allen seine Farbstifte spitzt \& für Euch mit der gesamten Kraft, mit der ganzen Magie seiner Farbenpalette die guten \& die schlechten Dinge Eurer so zivilisierten Gegenden vor Augen geführt hat. Sein Gemälde wird Euch vor Bewunderung bewegen, ich zweifle daran nicht: Aber glaubt Ihr, dass er in Euren Seelen die süße Gefühlsbewegung hinterlassen wird, die Ihr immer noch fühlt? ${ }^{38}$

Die in dieser Passage angestrebte Reaktion des Lesepublikums ist nicht ganz leicht zu fassen. Die Lektüre des vom Erzähler vorgelegten Berichts („récit“) soll bei dessen europäischen Adressaten starke Emotionen durch eine Art Hypotypose freisetzen, welche das vom mit Worten malenden Ich-Erzähler entworfene Bild in der Seele, im Innersten des Lesers bewahren wird. Das entworfene Tableau ist im Französischen ein Gemälde, aber auch ein Schema, eine Übersicht, eine statistische Aufstellung, und von daher ebenso textueller wie ikonischer Natur.

Es handelt sich dabei um ein rein sprachliches Verfahren, das wesentlich stärker und eindringlicher als das rein Visuelle und Ikonische ist, dem in der Histoire des deux Indes stets etwas Negatives, eine Art visueller Oberflächlichkeit, Naivität und fehlende geistige Durchdringung, anhaftet. Mit Worten und mit Zahlen zu malen aber ist die Sache unseres Berichterstatters, unseres Auctors,

38 Ebd., XV, S. 22. 
der sich für die Wahrhaftigkeit des von ihm Berichteten verbürgt. So erlaubt die einfache und poetische Sprache der Indianer Canadas Einblick in eine empfindsame und kindlich-offene Seele, die - folgen wir dem Erzähler - noch nichts von der Tiefe der Europäer besitzt:

Ihre Seele drückte sich so aus, wie ihre Augen es sahen: Es waren stets physische Wesen, die sie mit empfindsamen Farben malten, \& ihre Reden wurden malerisch-pittoresk. ${ }^{39}$

Wir haben es in diesem Zitat mit einer deutlichen Wertung der (sprachlichen) Ausdrucksfähigkeit der „Wilden“, also der indigenen Bevölkerung der Amerikas (welche ohne jede kulturelle Differenzierung als eine einzige homogene Bevölkerungsmasse gesehen werden), zu tun. Bei diesen sogenannten „Wilden“ erscheint die Beziehung zwischen Sprache und Bild, zwischen sprachlichem und bildhaftem Ausdruck seltsam verkehrt. Die der visuellen Wahrnehmung bei der indigenen Bevölkerung verhafteten Bilder der Seele verwandeln sich in einen malerischen (,pittoresque“) Diskurs, während der vom Erzähler arrangierte Bericht sich dank einer kunstvollen Gestaltung für den Leser in ein Bild, ein Gemälde transformiert. Stets sind es der Text und seine Lektüre, nicht aber die direkte Erfahrung, die dem Adressaten den Blick öffnen, die eine innere Vision ermöglichen, welche zweifellos der rein physischen Sinneswahrnehmung der Netzhaut überlegen ist. In gewisser Weise haben wir es hier mit einer entsakralisierten Fassung der topischen Metapher von den „Augen der Seele“ zu tun, die den christlichen Mystikern so teuer und Guillaume-Thomas Raynal, dem ehemaligen Schüler des Jesuitenkollegs in Rodez, gewiss bestens vertraut war.

Bei den ,wilden'Völkern hingegen beherrscht die direkte physische Erfahrung alles, die emotionalen Eindrücke nicht weniger als die sprachlichen Ausdrucksformen, in welche diese bei ihnen gekleidet werden. Der ,Wilde‘ liest nicht, er verfügt über keine Schrift, kein Schreib- und Zeichensystem. Im Grunde erübrigt sich an dieser Stelle der Hinweis, dass ein so verstandener und an der alphabetischen Schrift orientierter Begriff des ,Lesens‘ aus heutiger Sicht als Eurozentrismus angesehen werden darf. Denn die Verfasser der Histoire des deux Indes nahmen alle Schriftsysteme, welche nicht der alphabetischen Schrift entsprachen, nicht als ausgearbeitetes und differenziertes Zeichensystem wahr. Die europäische Aufklärung beachtete folglich nicht, was für die amerikanische längst eine Gewissheit war: die Anerkennung anderer, nicht-alphabetischer Schriftsysteme.

Die dem Vergleich zwischen ,peuples sauvages“ und „peuples policés“ zugrundeliegende Ambivalenz verweist uns auf das siebzehnte Buch, wo uns zugleich der zivilisatorische Prozess und der Prozess der Zivilisation dargeboten wird:

39 Ebd., S. 16. 
Ihr zivilisierten Völker, diese Parallele ist zweifellos schmerzlich für Euch: Aber Ihr würdet nur zu lebhaft unter der Last, unter der Ihr schmachtet und stöhnt, die Kalamitäten empfinden. Je mehr dieses Gefühl für Euch schmerzhaft ist, desto mehr wird es Eure Aufmerksamkeit schärfen für die wahren Gründe Eurer Übel. Vielleicht gelingt es Euch endlich, Euch davon zu überzeugen, dass sie ihre Quelle in der Entregelung Eurer Ansichten, in den Lastern Eurer politischen Verfassungen, in Euren bizarren Gesetzgebungen haben, durch welche die Gesetze der Natur fortwährend beleidigt werden. ${ }^{40}$

Der Blick in die weltweite Natur, der Blick in die verschiedensten Gesellschaften, die in der Histoire des deux Indes angesprochen und untersucht werden, erlaubt, ja zwingt förmlich $\mathrm{zu}$ einer Kritik der europäischen Institutionen und ihrer gesetzlichen wie wirtschaftlichen Grundlagen. Die ganze Ambivalenz eines derartigen Urteils wird deutlich, wenn Autor und Leser ihre „Blicke auf die physische Beschaffenheit“"41 der nordamerikanischen Welt werfen und dabei das Bild des (europäischen) Menschen entwerfen, der inmitten der „schöpferischen Kräfte“ der amerikanischen Natur erscheint:

Plötzlich erschien der Mensch, und das nördliche Amerika veränderte sein Antlitz. Er brachte die Regel \& die Sichel der Symmetrie mit sich, zusammen mit den Instrumenten aller Künste und Kunstfertigkeiten. Alsbald eröffneten sich ihm die vormals undurchdringlichen Wälder \& in den weiten Lichtungen wuchsen bald angenehme Wohnungen. Zerstörerische Tiere weichen vor den häuslichen Herden zurück: \& trockene Dornenfelder weichen üppigen Ernten. Die Wasser geben einen Teil ihrer Besitzungen auf \& ergießen sich durch tiefe Kanäle ins Innere der Erde oder in das Meer. Die Küsten bevölkern sich mit großen Städten, die Buchten mit Schiffen; \& die Neue Welt kommt unter das Joch des Menschen, ganz dem Beispiel der Alten Welt folgend. Welche mächtigen Triebkräfte haben diese wunderbaren Bauten des Gewerbfleißes \& der europäischen Politik errichtet? ${ }^{42}$

Selbstverständlich ist diese Frage eine rein rhetorische, denn nur zu genau kennt der Verfasser jene Triebkräfte, welche die Europäer in ihrer ständigen Expansion vorwärtstreiben. Es wäre überflüssig, an dieser Stelle alle Inszenierungen der Lektüre und ihrer Folgen für den Leser aufzulisten: Zu zahlreich sind diese literarischen Gestaltungen des Lesens textintern in der Geschichte beider Indien. Die Konsequenzen der Lektüre können für die Leserschaft im Übrigen positiv oder auch negativ sein. Wird etwa nicht von Beginn des ersten Buches der Histoire an behauptet, dass die Päpste - die zu den bevorzugten Zielscheiben dieses Bestsellers der französischen Aufklärung zählen - sehr früh schon verstanden hätten,

40 Ebd., XVII, S. 216.

41 Ebda.

42 Ebda., S. 217. 
dass die „Pflege der Literatur“, die „culture des lettres“, ihnen ein „,neues Mittel, um über die Geister zu herrschen“ an die Hand gegeben hatte ${ }^{43}$ ?

Zugleich ist es ein unhinterfragbares Dogma in der Geschichte beider Indien, dass die Schrift für die Menschen ein „mächtiges \& wohl einzigartiges Mittel der Erhellung“ darstellt, wobei unter dem Begriff der Schrift („écriture“) allein die alphabetische Schrift verstanden und andere Systeme wie etwa die „Unvollkommenheit der Hieroglyphen“44 und mehr noch die Pictogramme oder Knotenschriften (Quippus) der amerikanischen Welt verworfen und aus einer Fortschrittsgeschichte der Menschheit ausgeschlossen werden. Für die Verfasser der Histoire des deux Indes ist die (alphabetische) Schrift eine Kulturtechnik, die zwar auch im Sinne von Unterdrückung und Aberglaube verwendet werden könne, gleichwohl aber unersetzlich bleibt für die Verwirklichung des Fortschritts der gesamten Menschheit. Literatur, Philosophie und Naturgeschichte beschleunigen diese Bewegung mit Hilfe ihrer Einwirkung auf die Einbildungskraft, aber auch das intellektuelle Verständnis des Lesers:

Der Geist der Gesetze (l'esprit des loix) erschien, \& es erweiterte sich der Horizont für das Genie des Menschen. Die Naturgeschichte eines Französischen Plinius, welche Griechenland und Rom in der Kunst übertraf, die physische Welt zu erforschen \& zu malen; diese kühne \& wie ihr Gegenstand so große Geschichte, welche die Einbildungskraft der Leser erhitzte und sie an Betrachtungen fesselte, von denen ein Volk nicht herabsteigen darf, ohne nicht sogleich wieder in die Barbarei zurückzufallen. Dadurch wurde eine recht große Zahl an Bürgern über die wahren Bedürfnisse ihres Vaterlandes aufgeklärt. ${ }^{45}$

In diese Bewegung von Geschichte und Naturgeschichte, von Montesquieu und Buffon, von Wissenschaft und Philosophie schreibt sich die Histoire des deux Indes ganz bewusst ein. Dies hatte bereits unser Versuch einer ikonotextuellen ,Lektüre' des Frontispizes der erwähnten dritten Ausgabe der Histoire nahegelegt, wo bei aufmerksamer Betrachtung in unmittelbarer Nähe zur Feder des Schriftstellers die Bände der Encyclopédie sichtbar werden ${ }^{46}$ - und damit ein literarischer Raum, innerhalb dessen sich das eigene Schreiben des ins Zentrum gerückten Philosophen ansiedelt.

Das Vorhaben der Histoire des deux Indes ist wie die Projekte Buffons oder der Enzyklopädisten ganz auf die praxisbezogene Wirkung beim Lesepublikum abgestellt. Die Geschichte beider Indien will Wirkung erzielen, will gesellschaftsverändernd sein, will kurz gesagt die Welt der eigenen Gegenwart verwandeln.

43 Ebda., I, S. 25.

44 Ebda., VI, S. 254.

45 Ebda., XIX, S. 173.

46 Vgl. Ette, Ottmar: Diderot et Raynal, S. 385-407. 
Der Leser erscheint als Bürger, der auf Politik, Geschichte und die vorherrschenden Konzeptionen seiner Zeit einzuwirken vermag: als ein aktiver Bürger, den es zu beeinflussen und in seinen Handlungen zu lenken gilt, will man die Geschicke des Staates grundlegend verändern. Ohne diesen Hintergrund der Lektüre ist das revolutionäre Pathos der Geschichte beider Indien nicht zu verstehen.

Denn diese Vorstellung einer aktiven, schöpferisch umsetzenden Aneignung eines in Buchform präsentierten Wissens wird in der Histoire ständig propagiert, um damit die angezielte Leserschaft in ihrer Lesart gleichsam ,programmieren“ und lenken, man könnte auch sagen: besser manipulieren zu können. Über die Lektüre verbindet den Autor mit dem Leser ein Band, an welchem der Verfasser des Textes allein zu ziehen und zu zerren vermag. Dieses Lektüre- und Beeinflussungsmodell herrscht vor allem im externen Kommunikationsraum vor, insbesondere also hinsichtlich der in Szene gesetzten Beziehung zwischen explizitem Autor und explizitem Leser, die direkt miteinander kommunizieren, aber sich nicht auf derselben Augenhöhe ansiedeln. Denn längst hat sich der Autor Macht über seine zum Teil sehr einflussreichen Leser verschafft.

Wenn der Erzähler in der Kommunikation mit dem expliziten Leser auch des Öfteren versucht, dessen Einbildungskraft zu erhitzen, indem er ihm vorrangig schreckliche Geschehnisse und Aspekte der kolonialen Expansion Europas vor Augen (also vor die Augen des realen Lesers) führt, so ist der Aufruf zu einer kritischen Lektüre doch auch in der Histoire des deux Indes zu vernehmen. Diese kritische Lektüre siedelt sich vorrangig innerhalb des internen Kommunikationsraumes an. In diesem von der Orchestrierung der verschiedenen Stimmen beherrschten Raum dominiert - wie bereits erwähnt - unverkennbar die (literarisch in Szene gesetzte) Mündlichkeit.

Im Rahmen des internen Kommunikationssystems wird im Allgemeinen wenig gelesen. Taucht Lektüre dennoch auf, so geschieht dies fast immer, um den kritischen Geist des Erzählers als Leser anzustacheln, nicht aber, um die Qualitäten des gelesenen Werkes hervortreten zu lassen. Beispielsweise zieht der Erzähler bei seinen Bemerkungen zu den Marianen-Inseln die Beschreibungen durch die „alten wie die modernen Reiseberichte“ in Zweifel, wobei er betont, die einhellige Meinung der Historiker dürfe niemals „die Zweifel, welche ein so unwahrscheinlicher Bericht entstehen lassen musste ${ }^{\text {“47 }}$ im Keime ersticken. Oftmals wird die Kategorie des Wahrscheinlichen beschworen, um den spanischen Chronisten jedwede Glaubwürdigkeit zu entziehen. Aus der aufklärerischen und damit höheren Warte der Philosophie sind all diese spanischen Quellen höchst verdächtig und folglich frag- und unglaubwürdig. Das

47 Raynal, Guillaume-Thomas: Histoire, VI, S. 311. 
„Wunderbare“ („,merveilleux“) ihrer Berichte wird kritischen Reflexionen unterzogen, die auf eigener Leseerfahrung, bisweilen aber auch auf der Erfahrung bestimmter ,aufgeklärter Geister“ fußt, deren Namen der Erzähler freilich stets zurückhält. ${ }^{48}$ Spanische Quellen stehen, von wenigen Ausnahmen abgesehen, folglich unter französischem Generalverdacht.

An dieser Stelle wird der Erzähler wieder zum obersten Richter, der sich allein auf die verschiedensten Texte stützt, nicht aber auf Besichtigungen vor Ort und direkte Kontakte mit jenen, die er nach seinen eigenen Gesetzen literarischer oder philosophischer Wahrscheinlichkeit beurteilt beziehungsweise verurteilt. Dieser oberste Richter hält nichts von solchen Besichtigungen, nichts von empirisch überprüfbarem Wissen, sondern argumentiert gänzlich in einem eigenen Textuniversum, in welchem er gleichsam als vorgeblich kritischer Philologe vorgeht. Anlässlich der Erörterung der Schriften Acostas und Herreras räumt er zwar ein, dass bestimmte Irrtümer unterlaufen könnten, denn sie „gehen von einem Werk ins andere über \& Autoren, die wechselseitig voneinander abschreiben, übertragen diese Irrtümer von einem Zeitalter auf das nächste““ ${ }^{49}$ Jedoch ist er aller vorgeblichen Textkritik zum Trotz noch weit davon entfernt, diesen Teufelskreis unreflektierter Intertextualität zu durchbrechen, ordnet sich sein eigenes Werk doch in eine derartige Textkette fraglos ein.

Die getroffenen Vorsichtsmaßnahmen, um derartigen Textketten nicht auf den Leim zu gehen, sind freilich qualitativ wie quantitativ als gering zu veranschlagen. Eine kritische Durchsicht von Textinhalten anhand einer empirisch wie auch immer überprüfbaren Analyse erfolgt nicht: An Bezugstexten wird einbezogen, was dem Gutdünken des Verfassers und Herausgebers als zustimmungsfähig erscheint. Der Erzähler besteht lediglich ganz allgemein auf der Notwendigkeit einer kritischen Lektüre, die zweifellos auch für die Leserschaft der Histoire des deux Indes Modellcharakter haben soll. Diese kritische Lektüre ist aber ihrerseits nicht mehr an eine notwendige selbstkritische Sichtweise, an eine kontrollierende Lektüre der eigenen Schriften und ihrer literarischen Verfahren zurückgebunden.

An dieser Stelle sei lediglich darauf hingewiesen, dass der junge Alexander von Humboldt von anderen epistemologischen Voraussetzungen ausgehend Raynals Werk den (zumindest vorläufigen) Todesstoß versetzen sollte, fehlte den Schriften Raynals doch ebenso die Kontrolle durch direkte Erfahrung wie die Selbstkontrolle der narrativen und diskursiven Instanzen. Diese bemächtigten sich des Gesamttextes allzu oft, öffneten sich aber gerade darum auch gegenüber neuen, nicht mehr faktenorientierten Lesarten ohne jede Kontrolle. Humboldt

48 Stellvertretend für viele andere Beispiele in der Histoire des deux Indes s.VII, S. 108. 49 Ebd., VI, S. 285. 
sprach von einer „glücklichen Revolution“, die um die Wende zum 19. Jahrhundert eingesetzt habe und sich nunmehr an empirisch überprüfbarem Wissen ausrichte. Seitdem haben sich naturwissenschaftlich oder pragmatisch orientierte Leser kaum mehr um die von dem französischen Abbé zusammengetragene Histoire des deux Indes gekümmert. Eher historisch oder ästhetisch ausgerichtete Lektüren traten an ihre Stelle. Sie bemühten sich vorrangig um die Aufhellung von Genese, Struktur und innerer Funktionsweise des umfangreichen Textes, wie um dessen Wirkung an den verschiedensten Orten dieser Erde, bildeten selbst aber nicht mehr die Leitlinien von Forderungen und Einsichten ihrer Leserschaft. Diese auch längst im Sinne der Literaturgeschichte erfolgte ,Historisierung“ des Raynal'schen Werkes lässt für uns heute neue Verständnis- und Deutungsmöglichkeiten zu. Dies möchte ich zum Abschluss unseres Durchgangs durch das Hauptwerk des Abbé der Neuen Welt mit Blick auf die im Vordergrund stehenden Lektüreprozesse kurz ausführen.

Im Tableau de l'Europe. Pour servir de Supplément à l'Histoire philosophique \& politique des Etablissements \& du Commerce des Européens dans les deux Indes findet sich der nachfolgende Aufruf zur Lektüre, zum Lesen der eigenen Geschichte:

\begin{abstract}
Ihr Völker, bei denen die Könige heute all das anordnen und befehlen, was sie wollen, lest Eure Geschichte neu. Ihr werdet sehen, dass Eure Vorfahren sich versammelten, dass sie jedesmal beratschlagten, wenn es sich um Subsidien handelte. Ist die Gewohnheit dessen auch vergangen, so ging doch nicht das Recht darauf verloren; es steht an den Himmel geschrieben, der die Erde dem gesamten Menschengeschlecht gegeben, um sie zu besitzen; es steht auf diesem Feld geschrieben, das Ihr mühevoll umzäunt habt, um sich dessen Genusses zu versichern. Es steht in Euren Herzen geschrieben, wo die Gottheit die Liebe zur Freiheit eingeprägt hat. Dieser gen Himmel erhobene Kopf ist nicht nach dem Bilde des Schöpfers gemacht, sondern nur, um sich vor einem Menschen zu verneigen. ${ }^{50}$
\end{abstract}

Wir sehen sofort, welch wichtige, herausragende Funktion auch hier wieder dem Lesen der eigenen Geschichte zugewiesen wird. In diesem Auszug aus einem Text, den man mit Fug und Recht als das Supplément au voyage de Raynal bezeichnen könnte, wird der Appell an den Leser durch einen Appell an die Lektüre verdoppelt. Der Aufruf an die Völker, ihre Geschichte von neuem zu lesen, wird mit der Dissemination der Schrift über das gesamte Universum - im Himmel, auf Erden und in den Herzen der Menschen - verbunden. Überall ist diese Schrift lesbar und verlangt nach Leserinnen und Lesern, die sie sich aneignen und zueigen machen.

50 Raynal, Guillaume-Thomas: Tableau de l'Europe. Pour servir de Supplément à l'Histoire philosophique \& politique des Etablissements \& du Commerce des Européens dans les deux Indes. Amsterdam 1774, S. 128. 
Betont man in der Histoire des deux Indes auch, dass die Annalen der Völker nicht mehr von geschichtsforschenden Rednern, sondern vielmehr von Handel treibenden Philosophen verfasst werden müssten, ${ }^{51}$ so trägt doch die in diesem Supplément evozierte Schrift die Spuren der göttlichen Ecriture(s). Diese Schrift von neuem zu lesen heißt handeln, heißt, vor den Tyrannen nicht länger den Kopf zu senken. Der Appell an den Leser als Appell an eine wiederholte Lektüre wandelt sich zu einem „discours incendiaire“, ganz wie die Bewegung der Lektüre in revolutionäres Handeln umschlagen wird. Man versteht, warum der Abbé der Neuen Welt zum Zeitpunkt der Französischen Revolution als einer ihrer Hervorbringer, als einer ihrer Schöpfer gelesen und verstanden werden konnte.

Die Erwähnung und Bekräftigung des Lesens, der Lektüre, tendiert zumindest innerhalb des externen Kommunikationsraumes stets zur Aktion. Aus unserer Analyse der Lektüre in Raynals Hauptwerk geht nun deutlich hervor, warum der Aufruf zu ihr und ihrer Inszenierung im Verlauf der Histoire des deux Indes nicht so sehr ein intertextuelles als ein diskursives Phänomen war, das die kommunikative, synthetisierende und gesellschaftsverändernde revolutionäre Kraft der Lektüre ins Spiel bringt. Genau hier aber stellt sich für den Erzähler und Schriftsteller die Frage der Nachwelt und damit auch der (revolutionären) Nachkommenschaft.

Guillaume-Thomas Raynal blieb für seine Zeitgenossen nicht lange der „Vater der Revolution“, hatte ihn - wie Hans-Jürgen Lüsebrink mehrfach überzeugend dargestellt hat - seine Adresse à l'Assemblée Nationale doch in den Augen vieler Franzosen endgültig diskreditiert. Die zunehmende Autorisierung der Histoire des deux Indes konnte die noch zu Lebzeiten einsetzende wachsende Enteignung Raynals, die zeitweise durch die Entdeckung seiner Mitstreiter und vor allem Diderots beschleunigt wurde, nicht verhindern. Raynal galt immer weniger als der eigentliche Autor der Geschichte beider Indien und wurde zunehmend in jeglicher Hinsicht entautorisiert.

Doch dieser ,Abstieg‘ Raynals beschränkte sich keineswegs auf Frankreich, sondern entsprach gleichsam einer ,Entmündigung“ des französischen Philosophen ebenso in Europa wie auch gerade in den Amerikas. Der doppelte Verlust seiner ,Vaterschaft" bezüglich der revolutionären Ereignisse in Frankreich wie in Hinblick auf das unter seinem Namen veröffentlichte Werk ging - verbunden mit einer Reihe anderer, zu Beginn unserer Bechäftigung mit Raynal bereits kurz skizzierter Gründe - einher mit dem Verlust seines Prestiges bei den kreolischen Eliten, die sich durch einen französischen Philosophen zutiefst beleidigt fühlten. Denn dieser mit der Aura der Allwissenheit sich umgebende Philosoph reiste

51 Vgl. Raynal, Guillaume-Thomas: Histoire, VI, S. 199. 
selbst nicht und kannte weder ihre Länder noch ihre Lebensverhältnisse aus eigener Erfahrung. Welche Autorität konnte ihm also noch zukommen?

Wenn Raynal, ganz wie seine Erzählerfigur (und auch Diderot), kaum einmal seinen Fuß in andere Länder setzte und es vorzog, seine (europäischen) Leser zu einer Weltreise einzuladen, ohne Heim und Herd verlassen zu müssen, dann verhielt sich dies mit seinen Büchern keineswegs so. Denn diese reisten sehr wohl und ordneten sich dem zu, was wir in unserer Vorlesung als das Paradox über den Reisenden bezeichnet haben. Der Erzähler selbst hatte dies bei seiner Analyse der noch jungen Geschichte der Unabhängigkeit der Vereinigten Staaten klar erkannt und kommentiert:

Dieser Erfolg bildete den ersten Schritt des Englischen Amerika hin zur Revolution. Man ersehnte sie sich über alle Maßen. Man verbreitete überall die Prinzipien, welche sie rechtfertigten. Diese Prinzipien, welche in Europa \& insbesondere in England entstanden, waren vermittels der Philosophie nach Amerika transplantiert worden. Man wandte gegen die Metropole deren eigene Aufklärung an [...]. ${ }^{52}$

Auf eine ganz charakteristische, für die ins Auge gefassten historischen Prozesse zentrale Weise war die Revolution durch die kritische Philosophie der Aufklärung in die Amerikas gekommen: durch Transplantation. ${ }^{53}$ Mit anderen Worten: Es war eine République des Lettres entstanden, die nicht nur Frankreich mit allen Ländern Europas vereinigte, sondern eine Aufklärungsbewegung entstehen ließ, welche weltumspannenden Zuschnitts war. Und dies bedeutete, dass Texte nicht mehr allein im nationalen oder kontinentalen Rahmen, sondern wirklich transkontinental gelesen wurden und ein öffentlicher Raum entstanden war, innerhalb dessen sich die Ideen durch Lesen fortpflanzten.

Wäre auch die Behauptung übertrieben, die in den spanischen Kolonien Amerikas um sich greifende Unabhängigkeitsbewegung sei in Form von Büchern aus Europa per Schiff eingeführt worden, so gilt es doch $\mathrm{zu}$ verstehen und zu berücksichtigen, dass die wütenden Angriffe und Attacken des „discours incendiaire“ in der Histoire des deux Indes zusammen mit der vielfach wiederholten Inszenierung eines aktiven Lesers (der sich im Übrigen häufig zwischen divergierenden Ansichten in Raynals heterogenem Text entscheiden muss) nicht ohne Wirkung auf die Leserschaft in Europa, aber auch in Übersee bleiben konnten. Wir haben gesehen, wie Entrüstung und Revolte auf Seiten des expliziten Lesers in den Text selbst gleichsam als Rezeptionsvorgabe hineingespielt wurden. Diese

52 Ebda., XVIII, S. 150.

53 Vgl. hierzu Ette, Ottmar / Wirth, Uwe (Hg.): Kulturwissenschaftliche Konzepte der Transplantation. Unter Mitarbeit von Carolin Haupt. Berlin - Boston: Walter de Gruyter 2019. 
Emotionalisierung des Lesepublikums wirkte in Zusammenhang mit den transportierten und transplantierten Ideen durchaus wie diskursiver Sprengstoff, der jederzeit auch fernab der Metropole an der Seine explodieren konnte.

Die Inszenierung der Lektüre sollte im externen Kommunikationsraum der Histoire des deux Indes auf eine Aktivierung des Lesers abzielen. Dies gelang, und daher kam dieser in Europa während mehr als hundert Jahre in Vergessenheit geratene Text doch noch zu seiner ersehnten Nachkommenschaft. So hat der zweifach seiner Vaterschaft beraubte Guillaume-Thomas Raynal, jener sesshafte Reisende, der sich der direkten Erfahrung der außereuropäischen Welt trotzig und überlegen als Daheimgebliebener entgegenstellte, im Bereich des politischen Handelns wie der Philosophie- und Literaturgeschichte eine doppelte Nachwelt gefunden. Gewiss wäre es allzu simplistisch, wollte man die Haitianische Revolution oder die in den spanischen Kolonien ausbrechende Unabhängigkeitsrevolution auf die Lektüre der Schriften Raynals zurückführen. Aber ihren Anteil an dieser Transplantation von Ideen in die Amerikas hatte die Geschichte beider Indien. Mehr als zweihundert Jahre nach dem Tode Raynals darf man unpathetisch festhalten, dass seinen Texten eine weltweit verstreute Nachkommenschaft und eine heute wieder wachsende Leserschaft zuteil geworden sind.

Doch gehen wir nun von unserer vertieften Auseinandersetzung mit der politischen Relevanz und der Machtbedeutung der Lektüre im 18. Jahrhundert über zum Schreiben und Lesen der Liebe im Jahrhundert der Aufklärung. Denn die République des Lettres befasste sich nicht allein mit der militärischen, kolonialen und wirtschaftlichen Expansion Europas oder mit einer politischen Revolution im nationalen Maßstab, sondern auch mit jenen Veränderungen im Verhalten der Geschlechter, welche sich in der Epoche der philosophes ereigneten.

Im Zeichen von libertinage und Erotomanie vollzogen sich durchaus einschneidende Umorientierungen in der Fokussierung der Liebe, auch und gerade bezüglich der Zahl der Liebespartnerinnen und -partner. Das 18. Jahrhundert bildete ein weites Experimentierfeld für Liebesbeziehungen verschiedenster Art, welche erst seit der zweiten Hälfte des 20. Jahrhunderts wieder freier diskutiert werden konnten. Hier lässt der Marquis de Sade, der ab den späten sechziger Jahren des letzten Jahrhunderts eine starke Kanonisierung erfuhr und sogar zur Schullektüre in Frankreichs Collèges avancierte, uns recht herzlich grüßen.

Diese Veränderung in den Geschlechterbeziehungen betraf nicht nur die Tatsache, dass man als Frau von Stand nicht nur einen Ehemann von Stand, sondern auch einen quasi-offiziellen Geliebten, einen amant en titre, ebenso besaß wie auch weitere Geliebte, die man mit einer gewissen Regellosigkeit auswechseln konnte. Man amüsierte sich in höheren gesellschaftlichen Kreisen recht intensiv. Dass hierin auch der katholische Klerus miteinbezogen war, ist in vielen Dokumenten belegt. Denn längst hatte das Ancien Régime der Liebe aufgehört, 
weiterhin einzig dominant zu sein: Längst hatten sich neue Liebespraktiken entwickelt, mit denen munter experimentiert wurde. In der Folge wollen wir uns in der Vorlesung auf die Suche nach diesen Veränderungen begeben, wobei wir als unseren Cicerone einen weithin bekannten, Latin Lover ausgesucht haben, der uns auf diesem Weg ein wenig begleiten wird. 